\title{
The impact of low concentrations of aflatoxin, deoxynivalenol or fumonisin in diets on growing pigs and poultry
}

\author{
Yueming Dersjant-Li, Martin W. A. Verstegen and Walter J. J. Gerrits* \\ Animal Nutrition Group, Department of Animal Science, Wageningen University, PO Box 338, \\ 6700 AH Wageningen, The Netherlands
}

\begin{abstract}
In the present review, the quantitative impact of dietary aflatoxin, deoxynivalenol (DON) and fumonisin concentrations on performance of pigs and broilers is evaluated, with special emphasis on low concentrations of these toxins. Also, responses in performance of pigs and broilers to these three toxins are related to their absorption and elimination kinetics. By applying simple linear regression, information from many literature sources is integrated and condensed into, for example, estimates of depression in rates of weight gain, relative to non-contaminated diets, with increasing toxin concentrations. It was estimated that with each $\mathrm{mg} / \mathrm{kg}$ increase of aflatoxin in the diet, the growth rate would be depressed by $16 \%$ for pigs and $5 \%$ for broilers. For DON, with each $\mathrm{mg} / \mathrm{kg}$ increase in the diet, the growth depression was estimated at about $8 \%$ for pigs, while broilers showed no response to DON concentrations below $16 \mathrm{mg} / \mathrm{kg}$. Fumonisin showed the lowest impact on growth performance; with each $\mathrm{mg} / \mathrm{kg}$ increase, the depression in growth rate was estimated at 0.4 and $0.0 \%$ for pigs and broilers, respectively. Dietary concentrations that cause a $5 \%$ reduction in growth rate were estimated at 0.3 and $1.0 \mathrm{mg} / \mathrm{kg}$ for aflatoxin for pigs and broilers, respectively; 1.8 and $0.6 \mathrm{mg} / \mathrm{kg}$ for pure and naturally contaminated DON for pigs, respectively; 21 and $251 \mathrm{mg} / \mathrm{kg}$ for fumonisin for pigs and broilers, respectively.
\end{abstract}

Aflatoxin: Deoxynivalenol: Fumonisin: Toxins: Farm animal nutrition

\section{Introduction}

Mycotoxins, produced as a result of fungal infestation of crops, are of worldwide concern for crop producers and consumers. There are a wide variety of toxins, produced by numerous fungi, depending on the type of crop, geographical location and climatic conditions. The mycotoxin content of harvested crops depends on growing and storage conditions, and can be increased in the case of physical damage of the crops, for example, as a result of insect infestation. Mycotoxins are a potential threat to human health. Joint FAO/WHO expert committees are providing estimates of relative health risks associated with specific proposed maximum limits for particular toxins. Feeding contaminated materials to animals, especially single-stomached animals, impairs feed intake, efficiency of feed utilization and/or animal health. Moreover, residues of mycotoxins, consumed by animals, can appear in animal products destined for human consumption, with aflatoxin M1 in milk being an obvious example. Accumulation of residues in edible animal products, however, depends on absorption and elimination kinetics, which differ between toxins and animal species. Knowledge of the effects of low mycotoxin intakes is of increasing interest because of potential long-term or cumulative effects (human consumers), or slightly (but significant worldwide) reduced animal performance. Increased variability in performance is also of concern.

Ingestion of mycotoxins can cause tissue and organ damage and can eventually result in death. Several reviews have been published on the effects of aflatoxin (Clarkson, 1979), deoxynivalenol (DON) (Rotter et al. 1996a) and fumonisin (Colvin et al. 1993; Diaz \& Boermans, 1994; Dutton, 1996) in farm animals. Most reviews, however, have focused on toxicological effects of a particular mycotoxin and its effect on animal health.

\footnotetext{
Abbreviations: AFB1, aflatoxin B1; DON, deoxynivalenol; FB1, fumonisin B1; 5GRC, $5 \%$ growth reduction concentration; iv, intravenous; MGR, marginal growth rate reduction.

* Corresponding author: Dr Walter J. J. Gerrits, fax +31 317 484260, email walter.gerrits@wur.nl
} 
Aflatoxins can be produced by three species of Aspergillus: A. flavus, A. parasiticus and the rare $A$. nomius, growing on a variety of feedstuffs, mainly in maize, peanuts and cottonseed. The most common aflatoxins are aflatoxin B1 (AFB1), aflatoxins B2, G1 and G2. Aflatoxins M1 and M2 are the hydroxylated metabolites of AFB1 and aflatoxin B2 and may be found in milk or milk products. AFB1 is an active hepatocarcinogen and is considered the most toxic of the aflatoxins. The fungus can only colonize kernels that have been damaged and grows best and with maximal toxin production at $18 \%$ moisture and a temperature of $25-26^{\circ} \mathrm{C}$ (Clarkson, 1979). Natural occurrence of aflatoxin in feed ingredients varies with growing and storage conditions, usually between 0 and $1 \mathrm{mg} / \mathrm{kg}$.

DON is produced by strains of Fusarium graminearum and F. culmorum. DON is one of the most common contaminants of wheat, maize, and barley worldwide (Rotter et al. 1996a). It is a very stable compound that does not degrade at high temperatures (Scott, 1991). Environmental conditions that favour DON production in the field are low temperature and high humidity. The natural occurrence of DON in feed ingredients mainly varies within 0 and $5 \mathrm{mg} / \mathrm{kg}$. The effect of dietary DON on pigs is characterized by feed refusal, with little permanent damage to tissues and organs.

Fumonisins are produced by $F$. verticillioides ( $F$. Moniliforme), $F$. proliferatum and $F$. napiforme. A fungus of Alternaria spp. was also shown to produce fumonisin B1 (FB1). The predominant molecular form produced by $F$. verticillioides strains is FB1. Fumonisins are mainly detected in maize and maize-based diets. Diaz \& Boermans (1994) reviewed the natural occurrence of fumonisins ranging between 0 to $10 \mathrm{mg} / \mathrm{kg}$. Ingestion of dietary fumonisins can cause porcine pulmonary oedema, which is characterized by severe lung oedema and hydrothorax (Harrison et al. 1990).

The natural contamination of feedstuffs by mycotoxins is often at lower concentrations than those used in an experimental setting. In addition, contaminated batches can be diluted before use in animal feed. Therefore, in the present review, the quantitative impact of dietary aflatoxin, DON and fumonisin concentrations on performance of pigs and broilers is evaluated, with special emphasis on low concentrations of these toxins. Furthermore, the quantitative responses of pigs and poultry to these toxins are compared and discussed in relation to their absorption, metabolism and elimination kinetics.

\section{Methodology}

Literature sources in which the responses of feed intake and growth rate were measured with increasing toxin intakes were included in the present study. Experimental data from these sources were subjected to the following analyses: within each trial within a study, data were analysed for the response of feed intake, growth rate and feed:gain to increased dietary toxin concentrations by simple linear regression. The results are presented in Tables 1-6. Integrating data from various studies, the relationship between dietary toxin concentrations and animal perfor- mance was analysed by pooling the data from different studies, using linear regression. This analysis was performed for each toxin for pigs and poultry separately and the results are presented in Figs. 1-6. Considering that the literature data were produced under different experimental conditions (such as feed quality, husbandry conditions and age of animals), the growth rates produced in different studies might not be comparable. Therefore, the reduction in growth rate, expressed as a percentage of that in animals fed a toxin-free control diet was calculated and used for the regression analysis. In this analysis, for reasons of simplicity, it has been assumed that all data points are equally important, regardless of the period of exposure to the toxins, number of replications, and the number of animals per replicate. Each experimental treatment was considered as one observation.

For the analysis of the data from different experiments, a straight line was fitted to the data $(Y=\mathrm{a}+\mathrm{b} X)$, in which $Y$ is depression in the rate of weight gain of pigs or broilers compared with the toxin-free control treatment, expressed as a percentage, $X$ is dietary toxin concentration $(\mathrm{mg} / \mathrm{kg})$, a is the intercept and $b$ is the slope of the relationship. Although theoretically, this relationship should not have an intercept, an intercept was included for the following reasons: (1) leaving the intercept out interferes with the accuracy with which the slope of the relationship can be estimated; (2) in some studies, naturally contaminated diets were used. Toxins, other than the one of interest, may, in these studies, have affected the growth rate of the animals. Also, these naturally contaminated diets can potentially have a lower nutritional value or specifically reduce feed intake (not directly related to the toxin studied) compared with the toxin-free control diet used in that particular study. Throughout the present paper, this marginal growth rate reduction (MGR) per $\mathrm{mg} / \mathrm{kg}$ increase in dietary toxin concentration is indicated $(\% / \mathrm{mg}$ per $\mathrm{kg})$.

Different studies varied with regard to the origin of the toxin, including purified toxins, toxins from cultured material or from naturally contaminated materials. When there were sufficient data available for each toxin origin, the data were analysed for purified and naturally contaminated (and cultured) toxin origins separately (for DON). When data were not sufficient, the pooled data for toxin from all origins were used for the analysis.

The lowest concentration at which a toxin affects animal performance (threshold concentration) is an interesting parameter for nutritionists, but impossible to analyse in data pooled across studies. It was therefore arbitrarily chosen to present the toxin concentration that causes a $5 \%$ reduction in growth rate relative to a toxin-free control diet as a biologically significant effect, throughout the present paper indicated as the $5 \%$ growth reduction concentration (5GRC; $\mathrm{mg}$ toxin $/ \mathrm{kg} \mathrm{diet).} \mathrm{A} 5 \%$ reduction in growth rate is quite significant to farmers and is usually within the power of an experiment. Because the intercept of the regression line (a) was positive in some cases (see Figs. $1-6)$, the 5GRC $\left(X_{5}\right)$ was calculated as follows. When the intercept a is positive, $X_{5}=5 / \mathrm{b}$; when the intercept a is negative, $X_{5}=(5-\mathrm{a}) / \mathrm{b}$. The $5 \mathrm{GRC}$ calculated from the regression analysis was compared with studies in which low toxin doses were used. 


\section{Results}

\section{Aflatoxins in pigs}

Literature data on the effect of aflatoxin on growth performance of pigs are summarized in Table 1 . The tested aflatoxin concentrations in the diets used in these literature sources ranged from $0 \cdot 2$ to $4 \mathrm{mg} / \mathrm{kg}$. Either naturally contaminated or cultured material was used in these studies as specified in Table 1. Fig. 1 presents the response of growth performance of pigs (expressed as percentage decrease as compared with the toxin-free control group) to increased aflatoxin concentrations, obtained by pooling all literature data. Generally, the rate of weight gain decreased linearly with increasing aflatoxin concentrations in the diets. The MGR and 5GRC for aflatoxin in pigs were estimated at $16 \% / \mathrm{mg}$ per $\mathrm{kg}$ and $0.3 \mathrm{mg} / \mathrm{kg}$, respectively.

The decreased growth rate with increasing aflatoxin concentrations in the diet was mainly related to the reduced feed intake. With increasing dietary aflatoxin concentrations, feed intake was linearly decreased. The effect of aflatoxin on feed:gain, however, was inconsistent (see Table 1). Some studies showed an increase in feed:gain (Armbrecht et al. 1971; Southern \& Clawson, 1979; Lindemann et al. 1993 (trial 1)), whereas others showed no effect (Harvey et al. 1989; 1995b; Lindemann et al. 1993 (trial 2)).

The estimated 5GRC for aflatoxin in pigs $(0.3 \mathrm{mg} / \mathrm{kg})$ was high compared with literature sources in which comparable aflatoxin concentrations were tested. Panangala et al. (1986) reported that an AFB1 concentration of $0 \cdot 3 \mathrm{mg} / \mathrm{kg}$ reduced feed intake and weight gain of pigs by 28 and $22 \%$ respectively compared with a toxin-free control group. It should be noted that Panangala et al. (1986) were not clear about the contamination levels used; they erroneously used $\mathrm{mg} / \mathrm{kg}$ and parts per billion as equivalents. In the present paper it has been assumed that the contamination levels in

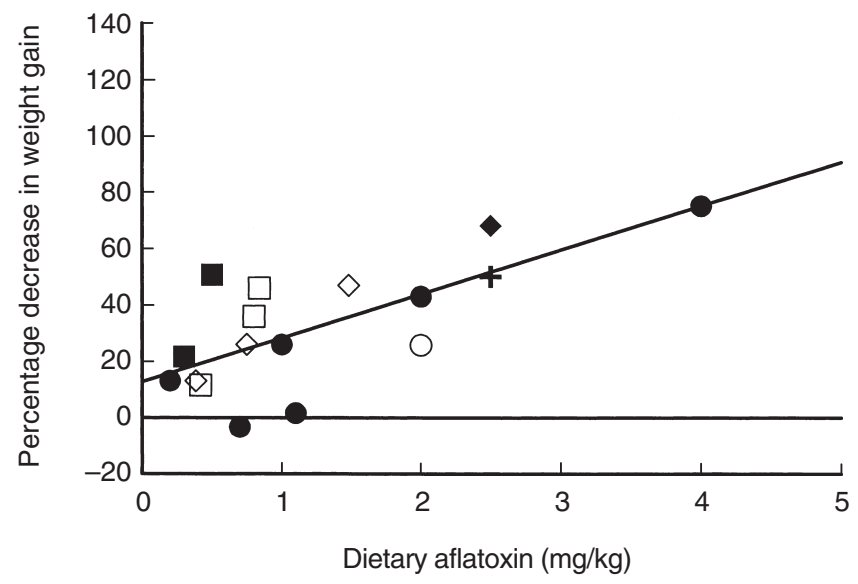

Fig. 1. The relationship between dietary aflatoxin and decrease in weight gain of pigs relative to a toxin-free control group $(Y=12 \cdot 7+$ 15.6X; $R^{2}$ 0.52). Data were derived from Table 1: (0), Harvey et al. (1989; cultured material); (๑), Armbrecht et al. (1971; cultured material); (), Lindemann et al. (1993; naturally contaminated material); (घ), Panangala et al. (1986; naturally contaminated material); $(\diamond)$, Southern \& Clawson (1979; naturally contaminated material); (+), Harvey et al. (1995a; naturally contaminated material); $(\diamond)$, Harvey et al. (1995b; naturally contaminated material). the work of Panangala et al. (1986) are parts per billion. Southern \& Clawson (1979) found that pigs fed a diet containing $0.385 \mathrm{mg}$ aflatoxin $/ \mathrm{kg}$ reduced feed intake and weight gain by 12 and $13 \%$, respectively, compared with a toxin-free control group. The lower degree in reduction of feed intake and growth in the study of Southern \& Clawson (1979) compared with the study of Panangala et al. (1986) may be partly related to the composition of toxin. Panangala et al. (1986) used AFB1, whereas Southern \& Clawson (1979) used aflatoxin, which contained $74 \%$ AFB $1,7 \cdot 5 \%$ aflatoxin B2 and $18 \cdot 5 \%$ aflatoxin $\mathrm{G} 1$.

\section{Aflatoxins in broilers}

Literature data on the performance of broilers at different dietary aflatoxin concentrations are summarized in Table 2. The tested aflatoxin concentrations ranged between 0.07 to $10 \mathrm{mg} / \mathrm{kg}$ diet and originated from cultured materials, naturally contaminated feed or purified aflatoxin. Fig. 2 presents the response of growth performance of broilers (expressed as percentage decrease as compared with a toxin-free control group) to increased aflatoxin concentrations, obtained by pooling literature data. When the source of aflatoxin was not mentioned, the data were not included in the analysis. The MGR and 5GRC for aflatoxin in pigs, estimated from these data, were $5 \% / \mathrm{mg}$ per $\mathrm{kg}$ and $1 \mathrm{mg} / \mathrm{kg}$, respectively. Literature data indicated that the reduced growth rate with increasing aflatoxin concentrations in the diet is associated both with a reduced feed intake and an increased feed:gain. As illustrated by Fig. 2, responses to aflatoxin concentrations between 0.2 and $2.5 \mathrm{mg} / \mathrm{kg}$ in the literature are inconsistent. Mani \& Sundaresan (1998) reported that dietary AFB1 concentrations between $0 \cdot 2$ and $0.5 \mathrm{mg} / \mathrm{kg}$ significantly reduced weight gain of broilers, while feed intake numerically decreased and feed:gain numerically increased.

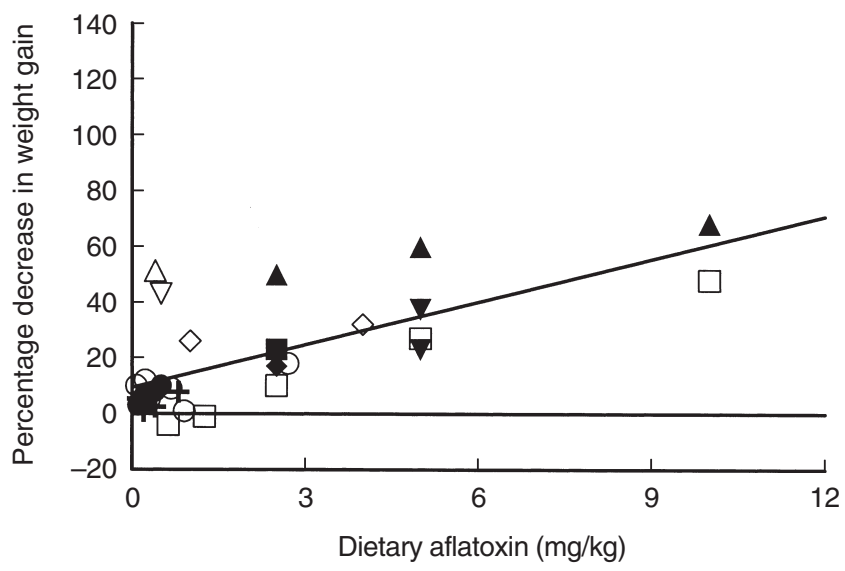

Fig. 2. The relationship between dietary aflatoxin and decrease in weight gain of broilers relative to a toxin-free control group $(Y=9.3$ $+5.1 X ; R^{2}$ 0.51). Data were derived from Table 2: (०), Doerr et al. (1983; cultured material); $(\bullet)$, Mani \& Sundaresan (1998; cultured material); (), Huff (1980; cultured material); $(\diamond)$, Ram et al. (1988; cultured material); ( $\diamond$, Huff et al. (1986; cultured material); (+), Giambrone et al. (1985; naturally contaminated material); $(\boldsymbol{\nabla})$, Randall \& Bird (1979; purified aflatoxin B1); $(\nabla)$, Prabaharan et al. (1999; unknown source); $(\Delta)$, Sodhi et al. (1996; unknown source); (ム), Shukla \& Pachauri (1985; unknown source). 


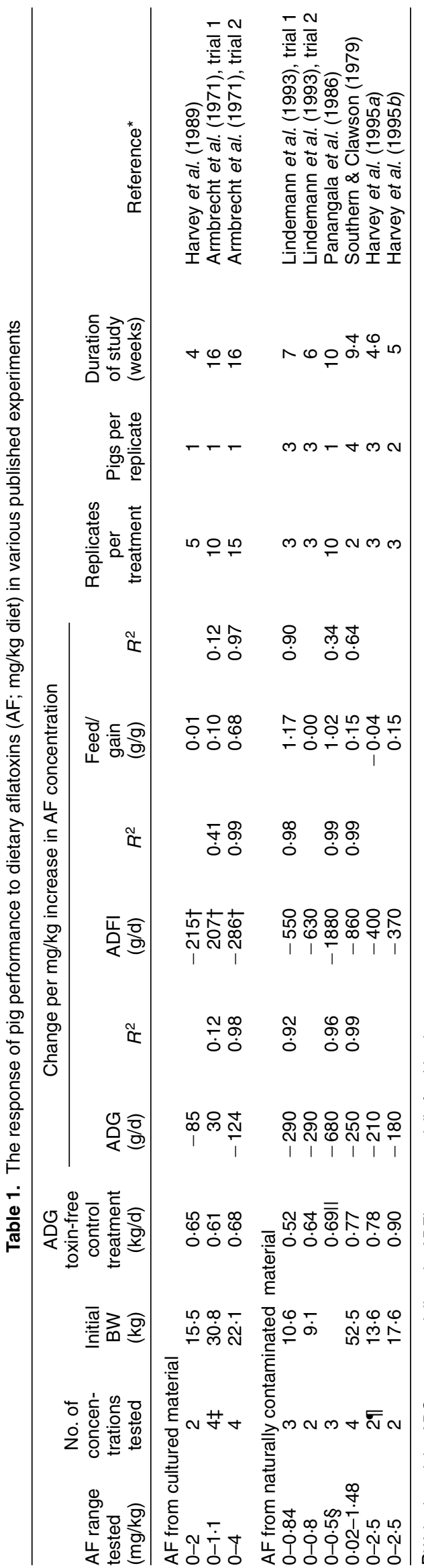

Similar results in depression in weight gain were also reported by Reddy et al. (1982), Doerr et al. (1983) and Sodhi et al. (1996). Giambrone et al. (1985), however, reported that dietary AFB1 ranging between $0 \cdot 1$ to $0 \cdot 8$ $\mathrm{mg} / \mathrm{kg}$ had no significant effect on body-weight gain; feed:gain was significantly higher in male broilers fed $0 \cdot 8$ mg AFB1/kg diet. Huff (1980) observed that aflatoxin concentrations below $2.5 \mathrm{mg} / \mathrm{kg}$ had no adverse effect on feed intake, growth and feed:gain in male broiler chicks.

\section{Absorption and elimination of aflatoxins}

General. According to Hsieh \& Wong (1994), AFB1 is rapidly absorbed from the small intestine into the mesenteric venous blood. After absorption, AFB1 is extensively transformed into metabolites (Eaton et al. 1994). Only a few percentage or less of the ingested dose was found to be excreted unchanged in several species (Lüthy et al. 1980). In rats, AFB1 is completely absorbed after an oral dose (Wogan et al. 1967, cited by Hsieh \& Wong, 1994). The liver is the principal site of accumulation of AFB1, metabolites and/or bound materials. Excretion of AFB1 and its metabolites occurs primarily with bile, and to a lesser extent with urine. Elimination of AFB1 appears slow in all species and strains studied. Wong \& Hsieh (1980, cited by Hsieh \& Wong, 1994) reported that the total excretion of ${ }^{14} \mathrm{C}$-labelled AFB1 was 80,72 and $73 \%$ of an intravenous (iv) administered dose in male mice, rats and monkeys, respectively, within $100 \mathrm{~h}$ after iv dosing. The excretion was most intensive during the first $24 \mathrm{~h}$ after dosing. On the other hand, it was reported that approximately $80 \%$ of a single intraperitoneal dose of ${ }^{14} \mathrm{C}$-labelled AFB1 in rats was excreted within $24 \mathrm{~h}$ post-injection (GN Wogan, cited by Mabee \& Chipley, 1973).

Pigs. The absorption and excretion kinetics of aflatoxin in pigs are similar to that in other species. Lüthy et al. (1980) examined the absorption and excretion rates of AFB1 after oral administration of ${ }^{14} \mathrm{C}$-labelled AFB1 in pigs. They concluded that aflatoxin was almost completely metabolized. They found that faecal excretion accounted for $58 \%$ of the dose after $9 \mathrm{~d}$, a large portion of which is expected to originate from biliary secretion. Recovery in urine was less than $15 \%$ of that ingested. They also observed the clearance rate of aflatoxin metabolites to be low in pigs; more than $20 \%$ of the dose was not recovered within $9 \mathrm{~d}$ after oral administration. Among tissues, the radioactivity was mainly recovered in the liver, followed by the kidney.

Poultry. Similarly to other species, aflatoxin is rapidly absorbed by poultry and slowly excreted. Sawhney et al. (1973) administered a single dose of ${ }^{14} \mathrm{C}$-labelled aflatoxin (11 mg/bird) via a stomach tube to laying hens. They found that only $28 \%$ of the dose was eliminated within the first $24 \mathrm{~h}$, while $71 \%$ of the dose was recovered within $7 \mathrm{~d}$ after administration of aflatoxin. A high concentration of radioactivity was found in bile, indicating aflatoxin is excreted mainly through bile. The accumulation of radioactivity was 


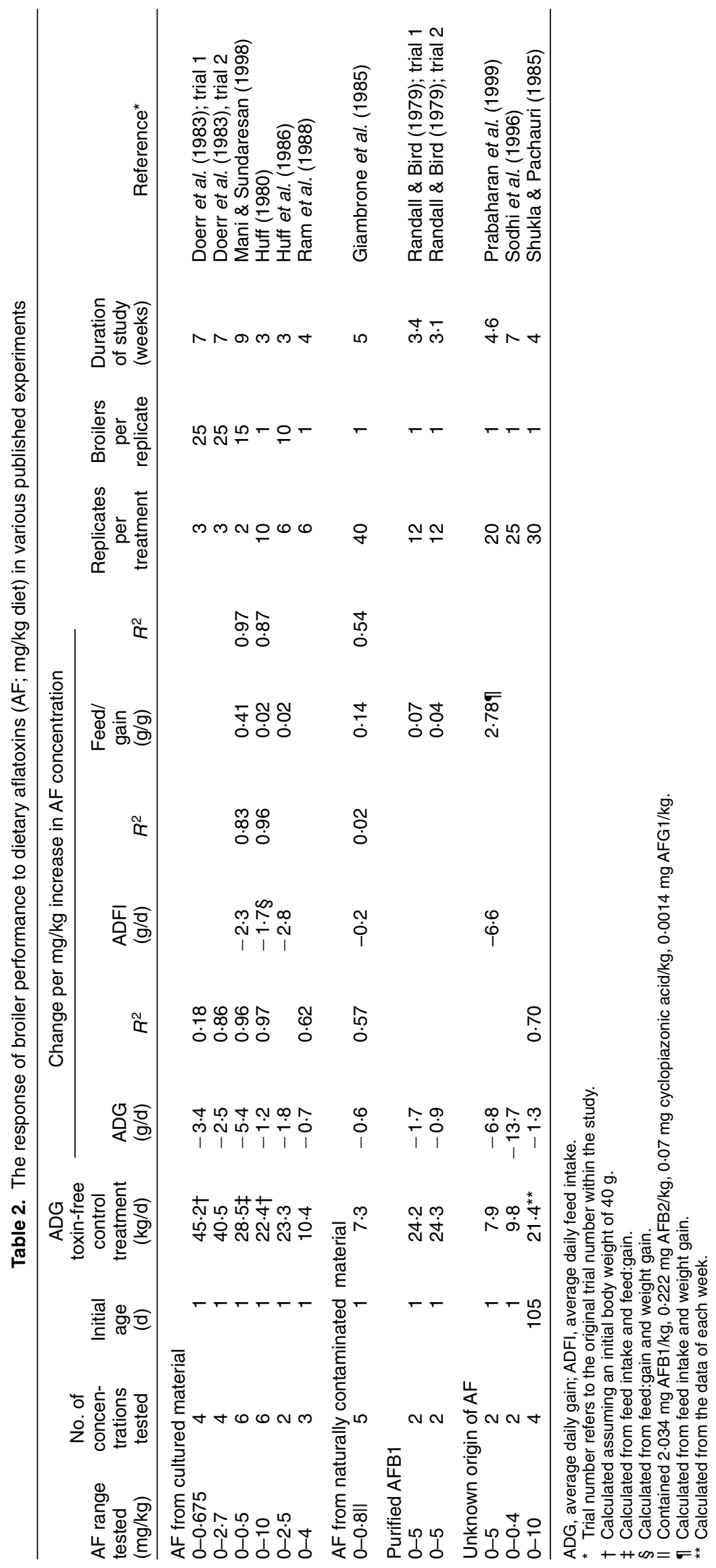


high in the liver and reproductive organs. The total accumulation of radioactivity in the organs was estimated as $1 \cdot 3,1 \cdot 0$ and $1.1 \%$ of the administered dose on day 1,4 and 7 , respectively. Mabee \& Chipley (1973) intubated laying hens daily with ${ }^{14} \mathrm{C}$-labelled AFB1 for $14 \mathrm{~d}$. They found that $5 \mathrm{~h}$ after the final dosing, the total radioactivity in organs and tissues accounted for nearly $8 \%$ of the cumulative administered dose in $14 \mathrm{~d}$. This amount was approximately equal to that amount in the final dose of AFB1, and so the authors concluded that most of the ${ }^{14} \mathrm{C}$-labelled AFB 1 administered in the previous $13 \mathrm{~d}$ was excreted before the final dose was given. This study suggests that continuous administration of aflatoxin may increase the excretion rate of aflatoxin compared with a single dose, although the quantity of aflatoxin intubated in a single dose can also influence the excretion rate.

\section{Deoxynivalenol in pigs}

Performance. Table 3 summarizes the literature data on the effect of DON on pig performance. In these studies, naturally contaminated or pure DON sources were used and the DON concentrations ranged between 1 and $20 \mathrm{mg} / \mathrm{kg}$ diet.

In Figs. 3 and 4, the pooled data are presented for naturally contaminated and pure DON separately. In the regression analysis, only DON concentrations below $20 \mathrm{mg} / \mathrm{kg}$ were used. The analysis showed that, based on these data, the MGR was 8.0 and $8.5 \% / \mathrm{mg}$ per kg for pure (Fig. 4) or naturally contaminated (Fig. 3) DON, respectively. The estimated 5GRC was 1.8 and $0.6 \mathrm{mg} / \mathrm{kg}$ for pure and naturally contaminated diets, respectively. However, as discussed later (p. 236), the adaptation of pigs to DON, when exposed longer than 1 week, complicates the comparison of experimental data obtained with varying exposure periods (Figs. 3 and 4). The reduced growth rate with increasing DON concentrations in the diet is mainly related to a reduced feed intake. However, an increased feed:gain with increasing DON concentration in the diet also contributes

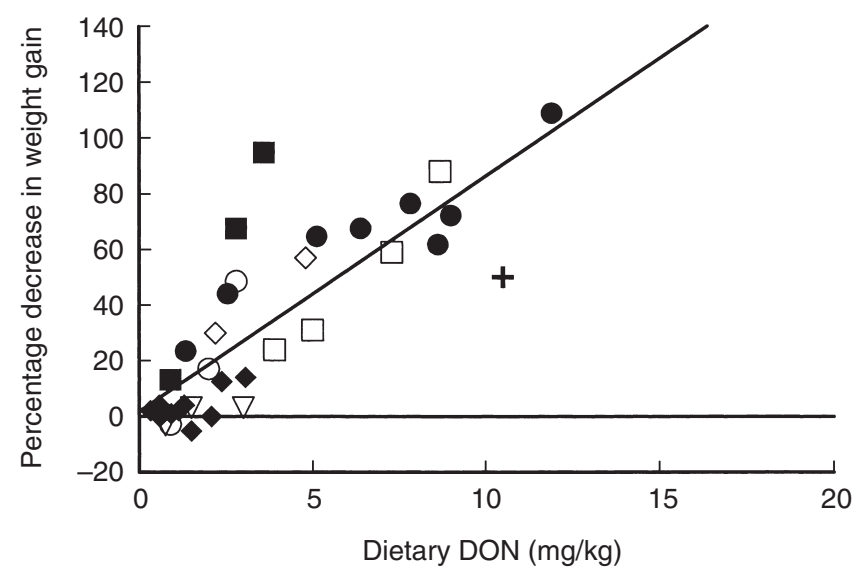

Fig. 3. The relationship between dietary deoxynivalenol (DON) from naturally contaminated material and decrease in weight gain of pigs relative to a toxin-free control group $\left(Y=1.71+8.45 X ; R^{2} 0.66\right)$. Data were derived from Table 3: (०), Pollmann et al. (1985); (•), Young et al. (1983); (口), Trenholm et al. (1994); (घ), Carlson et al. (1983); ( $\diamond)$, He et al. (1993); ( ), Friend et al. (1982); (+), Lun et al. (1985); ( $\nabla)$, Rotter et al. (1994). to the reduced growth rate. It should be noted, however, that a reduced feed intake automatically causes an increase in feed:gain, because maintenance energy becomes a greater proportion of intake. According to Pollmann et al. (1985) and He et al. (1993), a reduced growth rate occurs at dietary DON concentrations above $2 \cdot 8 \mathrm{mg} / \mathrm{kg}$. For naturally contaminated DON, concentrations above $1-2 \mathrm{mg} / \mathrm{kg}$ can reduce feed intake and growth (Carlson et al. 1983; Young et al. 1983; Pollmann et al. 1985) in pigs. Young et al. (1983) observed that a DON concentration of $1.3 \mathrm{mg} / \mathrm{kg}$ diet caused a significant depression in feed intake and growth rate; $12 \mathrm{mg} / \mathrm{kg}$ caused almost complete feed refusal and $20 \mathrm{mg} / \mathrm{kg}$ caused vomiting. He et al. (1993) found daily feed consumption, daily gain and feed efficiency to be decreased by 25,57 and $45 \%$, respectively, in pigs $(12 \mathrm{~kg})$ fed a $4.8 \mathrm{mg}$ DON $/ \mathrm{kg}$ diet compared with a toxin-free control diet during a $5 \mathrm{~d}$ period.

Dietary DON concentrations above $3-5 \mathrm{mg} / \mathrm{kg}$ originating from purified DON addition can decrease the performance of pigs. Apparently, pure DON has less severe effects on feed intake and growth of pigs compared with naturally contaminated DON (Foster et al. 1986; Trenholm et al. 1994), suggesting the occurrence of other toxins in naturally contaminated materials. Trenholm et al. (1994) concluded that feed intake and weight gain were respectively 18 and $23 \%$ lower when a diet containing naturally contaminated wheat was fed compared with a diet containing an equivalent concentration of pure DON. The results from our regression analysis presented earlier (p. 228), however, suggest a smaller difference.

\section{Deoxynivalenol in broilers}

Table 4 summarizes literature data on the effect of dietary DON on performance of broilers. The DON used in these studies was from naturally contaminated material, ranging between 0.3 to $16 \mathrm{mg} / \mathrm{kg}$ diet. Literature data on the effect of DON concentration on performance of broilers are scarce. It was, therefore, not possible to analyse the

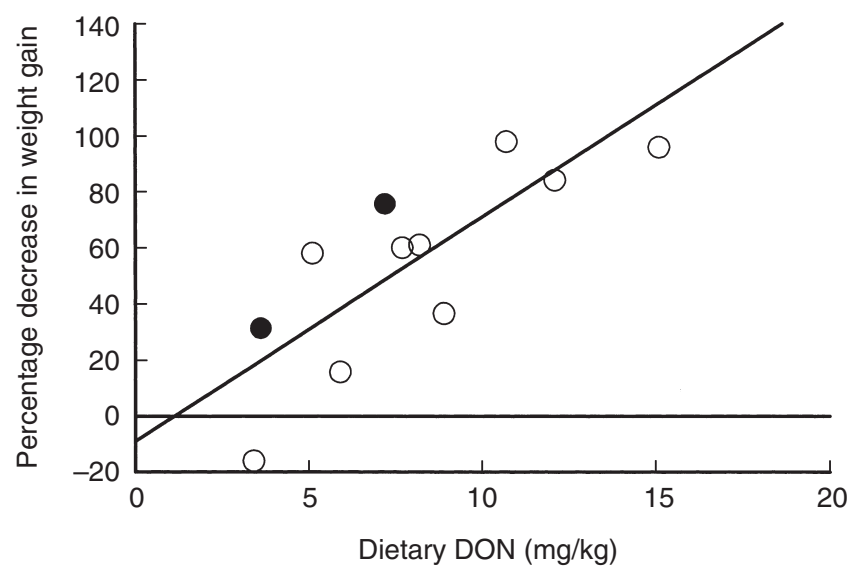

Fig. 4. The relationship between dietary deoxynivalenol (DON) from purified material and decrease in weight gain of pigs relative to a toxin-free control group $\left(Y=7.99 X-8.95 ; R^{2} 0.77\right)$. Data were derived from Table 3: (०), Trenholm et al. (1994); (•), Forsyth et al. (1977). 


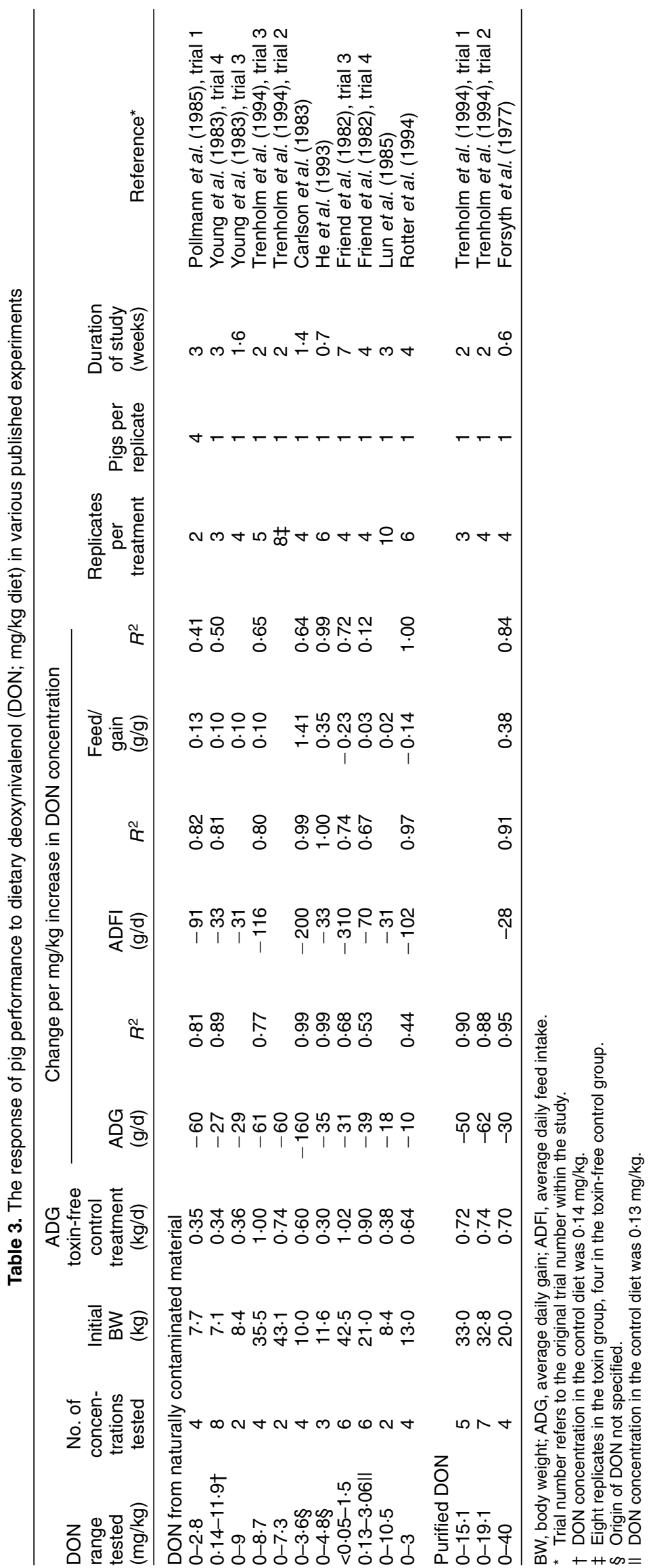




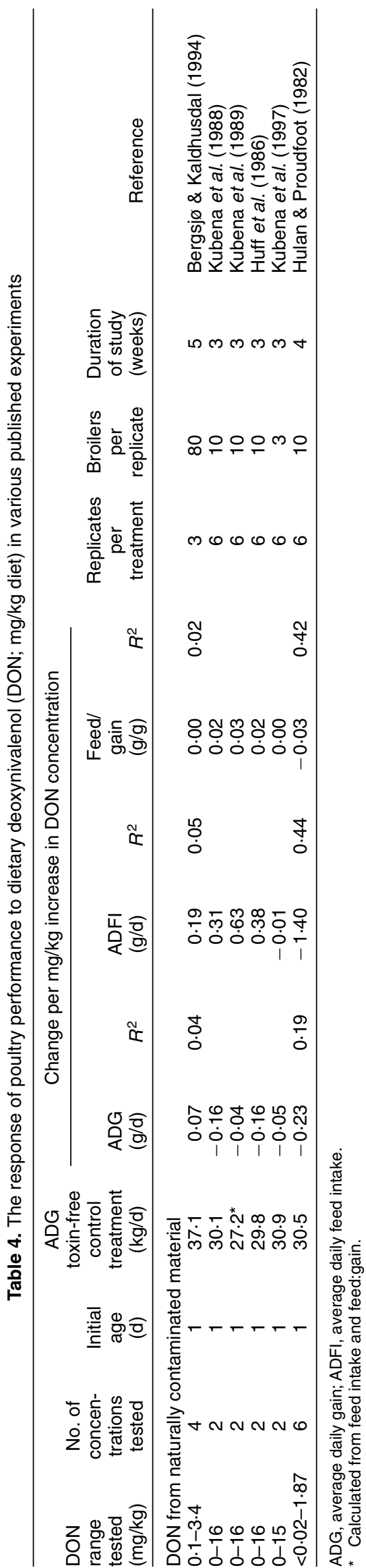

dose-response relationship between depression of growth in relation to dietary DON concentrations for broilers in a similar way as for pigs.

Above $16 \mathrm{mg} \mathrm{DON} / \mathrm{kg}$ diet, growth rate of broilers was depressed (Huff et al. 1986; Kubena et al. 1988). Unlike in pigs, feed intake was numerically increased in broilers fed a DON concentration of $16 \mathrm{mg} / \mathrm{kg}$ diet compared with the toxin-free control groups (Huff et al. 1986; Kubena et al. 1988, 1989). Kubena et al. (1989) observed a significant increase in feed:gain in broilers receiving $16 \mathrm{mg}$ DON/kg diet compared with the toxin-free control group. The available data indicated that concentrations of dietary DON below $15 \mathrm{mg} / \mathrm{kg}$ had no adverse effect on body-weight gain, feed consumption or feed:gain of broilers (Hulan \& Proudfoot, 1982; Bergsjø \& Kaldhusdal, 1994; Kubena et al. 1997).

\section{Absorption and elimination of deoxynivalenol}

Pigs. Friend et al. (1986b) estimated that at least $67 \%$ of the ingested DON was absorbed, based on the urinary recovery of DON and DOM-1, the latter being a de-epoxidated metabolite of DON. Absorption of DON from the pig gastrointestinal tract was very rapid. Peak plasma concentrations were reached within $30 \mathrm{~min}$ after intragastric administration and remained elevated for approximately $9 \mathrm{~h}$, declining slowly thereafter (Prelusky et al. 1988). Excretion of DON in pigs occurred through urine and bile pathways, with urinary elimination being by far the most important route. Prelusky et al. (1988) observed, in pigs, that 68 (SD 15) \% of intragastrically administered radiolabelled DON was recovered in urine, $2 \%$ was recovered in bile and 20 (SD 5.8) \% was recovered in faeces, within $24 \mathrm{~h}$. DON accounted for $>95 \%$ of the total measured radioactivity; metabolic conversion to DON conjugates was estimated to be less than $5 \%$. Following iv administration of ${ }^{14} \mathrm{C}$-labelled DON, 93.6 and $3.5 \%$ of the radioactivity was recovered in the urine and bile respectively, over a $24 \mathrm{~h}$ period. Over $75 \%$ of the dose was recovered within the initial $8 \mathrm{~h}$ after injection. These data indicate DON could be eliminated rapidly and completely within $24 \mathrm{~h}$ following a single iv or intragastric dose. Moreover, from the difference between the $24 \mathrm{~h}$ urinary recovery of intragastric and iv administration it seems that the absorption rate is lower than the urinary excretion rate. DON does not accumulate in tissues to any appreciable extent (Prelusky \& Trenholm, 1992).

Broilers. Prelusky et al. (1986) intubated ${ }^{14} \mathrm{C}$-labelled DON into chickens and found peak plasma concentrations occurring at $2 \cdot 0-2 \cdot 5 \mathrm{~h}$ after administration of labelled DON. They calculated the quantity of DON present in plasma at peak plasma concentration accounted for less than $1 \%$ of the administered dose. The fraction of the dose estimated to be distributed into tissues at the time of maximum absorption ( $3 \mathrm{~h}$ ) was on average only $1.3 \%$, and by $96 \mathrm{~h}$ after administration, the concentration of radioactivity in the tissues (not including gastrointestinal tract and bile) was only marginally detectable. Based on high specific activity measured in the bile samples and the relatively low systemic absorption of DON, these authors suggested 
biliary excretion played an important role in the elimination of DON from the body. They found the clearance rate of DON by chickens to be high; estimated recoveries of intubated DON in excreta were 58, 78, 90 and $99 \%$ at 12 , 24,48 and $96 \mathrm{~h}$ after intubation, respectively. In the same study, chickens were fed $2 \cdot 2 \mathrm{mg}$ unlabelled DON for $6 \mathrm{~d}$ followed by $2 \cdot 2 \mathrm{mg}{ }^{14} \mathrm{C}$-labelled $\mathrm{DON}$ for $6 \mathrm{~d}$. The residues contained in the edible tissues amounted to only 13-16 $\mu \mathrm{g}$ DON $/ 1.5 \mathrm{~kg}$ hen. No accumulation of radioactivity in tissues was observed. At $6 \mathrm{~d}$ after removal of the radiolabelled toxin, radioactivity concentrations in tissues were negligible.

\section{Fumonisin in pigs}

Performance. Table 5 summarizes the literature data on the effect of FB1 on pig performance. Studies were conducted by using naturally contaminated feed, cultured material or pure FB1. Most studies presented fumonisin concentrations as FB1; only the study of Motelin et al. (1994) used FB1 + fumonisin B2. For use in the present paper, the fumonisin concentrations in the study of Motelin et al. (1994) were recalculated as FB1. Dietary fumonisin concentrations varied between 0 and $200 \mathrm{mg} / \mathrm{kg}$. However, only low and high dietary fumonisin concentrations were tested; the data on intermediate concentrations are lacking. The available data do not allow reliable evaluation of the dose-response relationship between dietary fumonisin concentrations and the performance of pigs. When doing so anyway (see Fig. 5), the regression analysis revealed an MGR and 5GRC of $0.4 \% / \mathrm{mg}$ per $\mathrm{kg}$ and $21 \mathrm{mg} / \mathrm{kg}$, respectively. Literature data on growth responses of pigs to FB1 are, however, not consistent. For example, Guzman et al. (1997) reported that increasing dietary FB1 concentrations from 70 to $140 \mathrm{mg} / \mathrm{kg}$ decreased the rate of weight gain by 5 to $11 \%$. In contrast, Colvin \& Harrison (1992) reported that pigs surviving 4 weeks feeding

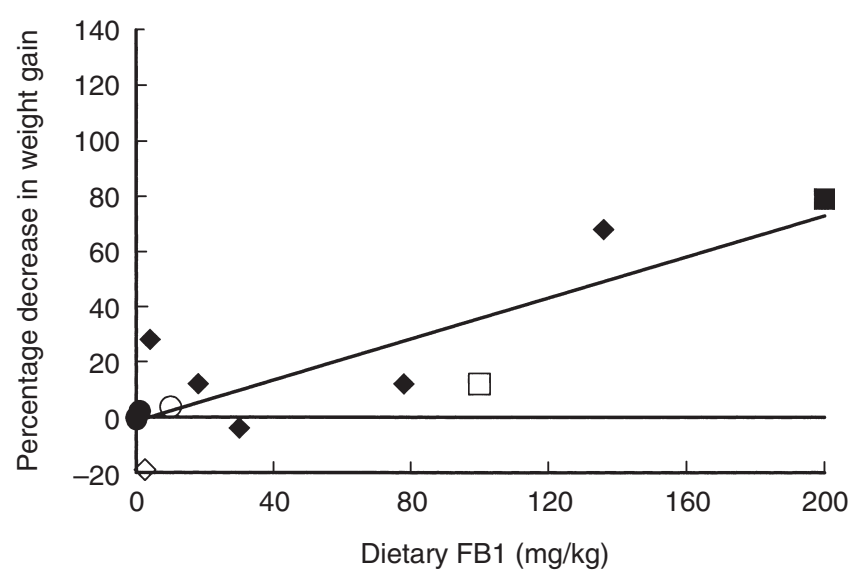

Fig. 5. The relationship between dietary fumonisin B1 (FB1) and decrease in weight gain of pigs relative to a toxin-free control group $\left(Y=0.37 X-1.59 ; R^{2} 0.74\right)$. Data were derived from Table 5: (०), Rotter et al. (1996b; purified FB1, average of male and female); (•), Rotter et al. (1997; purified FB1); (), Harvey et al. (1995a; cultured material); (₫), Colvin et al. (1993; cultured material); $(\diamond)$, Prelusky et al. (1996a; cultured material); ( ), Motelin et al. (1994; naturally contaminated material, recalculated as FB1). of diets containing 105 and $155 \mathrm{mg} \mathrm{FB} 1 / \mathrm{kg}$ diet were unable to maintain body weight. One pig died at day 7 after receiving $155 \mathrm{mg} \mathrm{FB} 1 / \mathrm{kg}$ diet due to pulmonary oedema and hydrothorax. The severity of the effect of FB1 in this study might indicate the presence of other toxins in the diet.

It is evident that dietary FB1 concentrations of 175-200 $\mathrm{mg} / \mathrm{kg}$ can have detrimental effects on pig performance (Colvin et al. 1993; Motelin et al. 1994). The reduced growth rate at high dietary fumonisin concentrations is clearly related to both a decreased feed intake (Colvin et al. 1993; Motelin et al. 1994) and an increased feed:gain (Motelin et al. 1994).

Pigs did not show a clear response in growth rate to dietary FB 1 concentrations below $40 \mathrm{mg} / \mathrm{kg}$. Rotter et al. (1997) found that pure FB1 concentrations of $0,0 \cdot 11$, 0.33 and $1 \mathrm{mg} / \mathrm{kg}$ diet did not affect growth, feed intake and feed efficiency of barrows from $25 \mathrm{~kg}$ initial weight to $101 \mathrm{~kg}$ final weight. However, the variation in feed intake increased when dietary FB 1 increased from 0 to 1 $\mathrm{mg} / \mathrm{kg}$. Zomborszkyne-Kovacs et al. (2000, not in Table 5) examined dietary FB1 concentrations of 10, 20 and 40 $\mathrm{mg} / \mathrm{kg}$ on the performance of weaned pigs for 4 weeks. They reported no effects on body-weight gain or on feed consumption. However, mild to severe pulmonary oedema was found in pigs fed FB1 diets. In contrast, Rotter et al. (1996b) showed a linear decrease in weight gain and feed intake of male pigs fed FB1 up to 10 $\mathrm{mg} / \mathrm{kg}$. This response, however, was not observed in females (Table 5). The feed:gain was, in general, not affected by dietary FB 1 concentrations below $175 \mathrm{mg} / \mathrm{kg}$ (Table 5). Remarkably, Prelusky et al. (1996a) and Rotter et al. (1996b) observed an increase in feed intake at low FB1 concentrations at the initial stage compared with a toxin-free control diet.

\section{Fumonisin in broilers}

Performance. Table 6 summarizes the literature data on the effect of fumonisin on broiler performance. Studies have been mainly carried out using material from $F$. verticillioides cultures. The tested concentrations of FB1 ranged between 10 and $475 \mathrm{mg} / \mathrm{kg}$. Most studies presented fumonisin concentrations as FB1; only the study of Wu et al. (1995) used total fumonisin. For the study of Wu et al. (1995), total fumonisin concentrations were recalculated as FB1.

The relationship between dietary FB1 concentrations and growth depression in broiler chickens was analysed based on the data from Table 6 (Fig. 6). The data of Espada et al. (1994) were excluded from the calculations of MGR and 5GRC because the birds had diarrhoea throughout the entire experiment. The estimated MGR and 5GRC were $0.02 \% / \mathrm{mg}$ per $\mathrm{kg}$ and $251 \mathrm{mg} / \mathrm{kg}$, respectively.

Literature studies showed inconsistent responses in growth rate of broilers with increasing dietary FB1 concentrations. Li et al. (1999) reported that increasing dietary FB 1 concentrations from 0 to $200 \mathrm{mg} / \mathrm{kg}$ had no significant effect on gain, feed intake and feed:gain. Wu et al. (1995) found FB1 concentrations of 50 and 99 $\mathrm{mg} / \mathrm{kg}$ diet depressed the growth rate of broilers. However, the feed intake was numerically higher in chicks fed FB1 

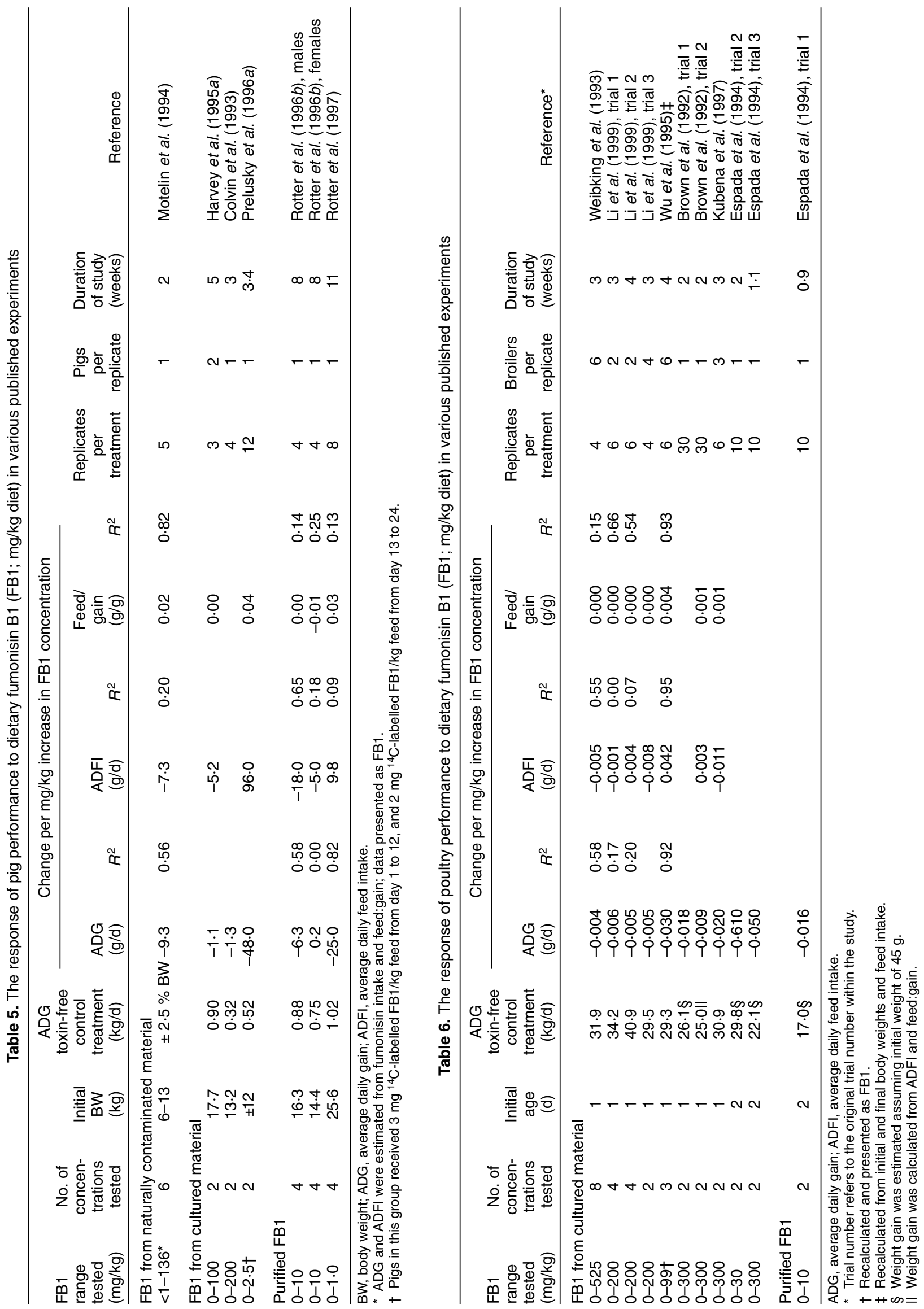


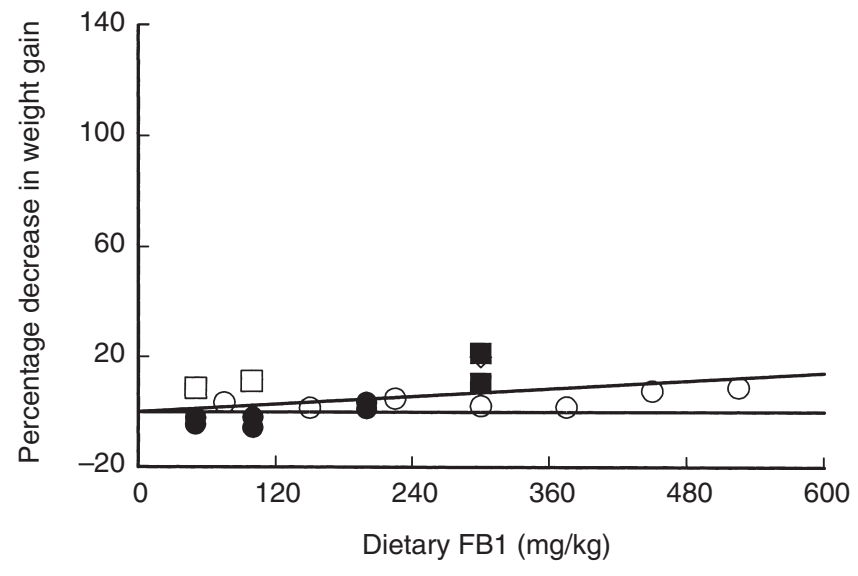

Fig. 6. The relationship between dietary fumonisin B1 (FB1) from cultured material and decrease in weight gain of broilers relative to a toxin-free control group $\left(Y=0.10+0.02 X ; R^{2} 0.20\right)$. Data were derived from Table 6: (०), Weibking et al. (1993); (•), Li et al. (1999); (), Wu et al. (1995, recalculated as FB1); (匚), Brown et al. (1992); $(\diamond)$, Kubena et al. (1997).

diets and the feed:gain was significantly increased at 99 $\mathrm{mg}$ FB $1 / \mathrm{kg}$. This may indicate increased energy expenditure of chickens consuming FB1 diets, probably due to an increased metabolic rate, energy costs involved in elimination of the toxin from the body or reparation of damaged tissues (increased protein turnover). Weibking et al. (1993) reported that depression in feed intake and growth rate occurred only when dietary FB1 concentrations were raised above $450 \mathrm{mg} / \mathrm{kg}$ in young broilers. On the other hand, however, Espada et al. (1994) found $10 \mathrm{mg}$ pure $\mathrm{FB} 1 / \mathrm{kg}$ and $30 \mathrm{mg} \mathrm{FB} 1 / \mathrm{kg}$ from cultured material depressed the growth rate of young chicks. However, in contrast to the toxin-free control group, birds receiving toxin diets suffered from diarrhoea, starting 3-6 d after receiving the FB1 diet, which persisted throughout a 5week recovery period. Weibking et al. (1993) did not observe diarrhoea in broilers fed diets containing FB1 up to $525 \mathrm{mg} / \mathrm{kg}$ and suggested diarrhoea would occur only when the concentration of cultured material exceeded 10 $\%$ of the diet. They suggested that an unknown toxic metabolite present in all $F$. verticillioides cultures at a low concentration may be the cause of the diarrhoea. The occurrence of diarrhoea and the possibility of the presence of other toxins or metabolites may explain the different response of growth performance of broilers to dietary FB1 among studies. Norred et al. (1991, cited by Weibking et al. 1993) indicated the presence of other cytotoxic watersoluble metabolites in $F$. verticillioides cultures. Consequently, the amount of cultured material or naturally contaminated material one has to include in the diet to realize a particular FB1 content in the diet can interact with the effects of dietary FB1 on performance of poultry.

\section{Absorption and elimination of fumonisin}

Pigs. Prelusky et al. (1996b) reported that after a single intragastric administration of ${ }^{14} \mathrm{C}$-labelled $\mathrm{FB} 1$ to pigs, radioactivity in the plasma reached peak concentration between 60 to $90 \mathrm{~min}$. After $180 \mathrm{~min}$, no radioactivity could be detected in plasma. They estimated that only about $4 \%$ of the intragastric administered dose was absorbed by the pigs. According to them, this may, however, be an underestimate because a part of the absorbed FB1 may be eliminated by the liver in the first pass. After a single intragastric dose of ${ }^{14} \mathrm{C}$-labelled FB1 to pigs $(0.5 \mathrm{mg} \mathrm{FB} 1 / \mathrm{kg}), 91.4 \%$ of the dose was recovered within $72 \mathrm{~h}$, with $90.8 \%$ in faeces and $0.6 \%$ in urine. However, $72 \mathrm{~h}$ after iv administration of labelled FB1 $(0.4 \mathrm{mg} \mathrm{FB} 1 / \mathrm{kg}), 58$ and $22 \%$ of the dose was recovered in faeces and urine, respectively, and on average $20 \%$ of the administered dose was still not recovered. The elimination of the iv-dosed FB1 was mainly through bile. The total amount of ${ }^{14} \mathrm{C}$ label in tissues, $72 \mathrm{~h}$ after iv administration was estimated at $10 \%$ in liver, $6.5 \%$ in muscle and $<1 \%$ in kidney. Following intragastric dosing, less than $1.5 \%$ of total dose remained in the tissues after $72 \mathrm{~h}$. At least $24 \mathrm{~h}$ was necessary before detectable concentrations were found in faeces. The work of Prelusky et al. (1996b) indicates absorption of FB1 in pigs is low. Elimination of absorbed FB1 is slow ( $80 \%$ in faeces + urine $72 \mathrm{~h}$ after iv administration), and strongly dependent on the biliary pathway. Prelusky et al. $(1996 a, b)$ also found accumulating tissue residues after prolonged exposure to a constant level of dietary FB1, and attributed this to enterohepatic circulation.

Broilers. Prelusky et al. (1996b) reported that estimated FB1 absorption by laying hens following oral dosing of ${ }^{14} \mathrm{C}$ labelled FB1 (2 mg/kg body weight) accounted for about 1 $\%$ of the administered dose. The FB1 was quickly eliminated after oral (97\% after $24 \mathrm{~h}$ ) and iv (99\% after $24 \mathrm{~h}$ ) administration. The accumulation of fumonisin in tissues is low. Vudathala et al. (1994) and Prelusky et al. (1996b) reported that $24 \mathrm{~h}$ after iv dosing, only traces of radioactivity were found in liver and kidney, and no radioactivity was detected in other tissues such as muscle, fat, heart, spleen and brains.

\section{Discussion}

In the present review, an attempt was made to quantify the response of swine and poultry, in terms of performance, to increasing toxin concentration in the diets. In reviewing the results reported in literature, various aspects were considered. Inevitably, however, by considering pooled results across experiments, valuable information on the biological effects of these toxins may be lost. In this discussion, attention focuses on methodological aspects of the data analyses, followed by a short summary of the effects of aflatoxin, DON and fumonisin in pigs and poultry. Finally, comparative aspects of the three toxins in pigs and poultry are discussed, with particular attention on the low-level toxicity in relation to natural occurrence of toxins, adaptive responses of animals to prolonged intakes, and toxin tolerance in relation to absorption and elimination kinetics.

\section{Methodological aspects}

Theoretically, the intercept of the regression line, meaning the response to zero intake, should be zero. In some cases 
(for DON in pigs and aflatoxin in both pigs and broilers), however, the analysed intercept of the linear regression is above zero. This may indicate the presence of other toxins or metabolites in naturally contaminated or cultured materials. Alternatively, it may imply a lower intake and/or digestibility of the contaminated feed ingredient, compared with the toxin-free feed ingredient used in the control diet. In addition, it may indicate the non-linearity of the response to increased toxin intakes. It should be noted that the data used in the present study allowed a separate analysis of the effect of different toxin sources (natural contamination, cultured material, purified toxins) on MGR and 5GRC only for DON in pigs. For aflatoxin and fumonisin in pigs and poultry and DON in poultry, data were pooled over toxin sources, but the sources are specified in the legends of Figs. 1 to 6 .

Given the variation in negative effects, it is clear that animal response to toxin intake can be influenced by many factors, including species, sex, age, health status, the nutritional balance and the hormonal status (for a review, see Hsieh, 1979). With regard to the depression of weight gain with increasing dietary toxin concentrations, in some cases (such as for fumonisin in broilers) inconsistent responses were observed across studies. These differences may be related to the following aspects: (1) the low number of replications used in some of the studies and the existence of large within-group variation (different responses between animals); (2) different exposure periods to the toxin applied in different studies. This is especially true in the case of DON in pigs. As discussed later in the present paper (p. 236), the period of exposure will affect growth depression, due to an adaptive response of pigs to DON (Table 3); (3) different amounts of contaminated materials added in the diets to formulate a tested toxin concentration in different studies, as mentioned earlier. The contaminated material may, independent from its toxin content, affect the growth rate by either reducing intake or increasing the feed:gain; (4) the physical condition and health status of animals may influence the response of animals to the toxin. For aflatoxin (Panangala et al. 1986), DON (Rotter et al. 1996a; Øvernes et al. 1997) as well as for fumonisin (Li et al. 1999), interactions between intake and immune function have been reported. It can therefore be expected that under suboptimal conditions, for example, exposure to pathogens, suboptimal housing conditions or ambient temperatures, the animal response to toxin intake may be affected.

\section{Aflatoxin}

The 5GRC caused by dietary aflatoxin was estimated at $0 \cdot 3$ and $1 \mathrm{mg} / \mathrm{kg}$ for pigs and broilers, respectively. The estimated 5GRC for aflatoxin in pigs was high when compared with literature sources in which comparable aflatoxin concentrations were tested. This is probably related to the high intercept and illustrates the need for more data at low concentrations. The responses of broilers to aflatoxin in different literature sources are inconsistent. Consequently, it is difficult to determine the minimum effect level from literature data. From the available information, the estimated MGR was 16 and $5 \% / \mathrm{mg}$ per $\mathrm{kg}$ for pigs and broilers, respectively, indicating the high toxicity of aflatoxin in these species. The reduced growth rate with increasing aflatoxin concentrations in the diet is related to both reduced feed intake and increased feed:gain. Concentrations of aflatoxin above $0.4 \mathrm{mg} / \mathrm{kg}$ can cause organ damage in pigs. More data are needed to quantify the response of pigs at low dietary aflatoxin concentrations (below $1 \mathrm{mg} / \mathrm{kg}$ ).

\section{Deoxynivalenol}

In pigs, the 5GRC for DON, based on pooled literature data, was 1.8 and $0.6 \mathrm{mg} / \mathrm{kg}$ for pure and naturally contaminated DON, respectively. This is in agreement with most studies performed at low DON intakes (Table 3), which indicates a concentration of DON of $1 \mathrm{mg} / \mathrm{kg}$ from naturally contaminated toxin can reduce the rate of weight gain and feed intake. In pigs, the MGR was estimated at about $8 \% / \mathrm{mg}$ per $\mathrm{kg}$. Diets with naturally contaminated DON more severely affected performance of pigs than pure DON. The reduced weight gain was mainly related to reduced feed intake. However, at dietary DON concentrations above $3 \mathrm{mg} / \mathrm{kg}$, feed efficiency was also decreased, which also contributed to the depression in weight gain of pigs fed DON-contaminated diet. The high $R^{2}$ for the average daily gain and the average daily feed intake in Table 3 illustrate the linearity in depression of average daily gain and average daily feed intake with increasing DON concentrations in pig diets. The depression of feed intake and growth rate was more severe in the first week, after which pigs showed some degree of adaptation. For broilers, lack of data prevented estimation of a relationship between growth rate and increasing dietary DON concentrations. Literature data indicated that only DON concentrations above $16 \mathrm{mg} / \mathrm{kg}$ can reduce weight gain (Huff et al. 1986; Kubena et al. 1988). This concentration, however, resulted in an increase in feed intake. The reduced weight gain, therefore, is associated with an increased feed:gain.

\section{Fumonisin}

From regression analysis, the estimated 5GRC for dietary fumonisin was 21 and $251 \mathrm{mg} / \mathrm{kg}$ for pigs and broilers, respectively. The MGR was estimated at 0.4 and $0.0 \% / \mathrm{mg}$ per $\mathrm{kg}$ for pigs and broilers, respectively. These data indicate the low acute toxicity of fumonisin when compared with the other toxins studied. Literature data are not sufficient to determine the minimum-effect levels in pigs. For broilers, it is difficult to determine the minimum-effect levels because of the large variation in responses between studies. In general, consistent performance depression in pigs and poultry was reported with fumonisin concentrations above $100 \mathrm{mg} / \mathrm{kg}$ in the diet. In young piglets, however, growth depression was also observed at concentrations between 0 and $10 \mathrm{mg} / \mathrm{kg}$ (Rotter et al. $1996 b$, Table 5). Remarkably, this effect was observed for male piglets, but not for females. The biological mechanism behind this sex difference was not clarified. Organ damage may occur at fumonisin concentrations above 23 $\mathrm{mg} / \mathrm{kg}$ for pigs (Motelin et al. 1994) and $75 \mathrm{mg} / \mathrm{kg}$ for broilers (Weibking et al. 1993). 


\section{Comparative aspects of aflatoxin, deoxynivalenol and fumonisin in pigs and broilers}

Table 7 summarizes the main characteristics of the impact of aflatoxin, fumonisin and DON on pigs and broilers. This table is compiled from the data of Tables 1-6.

Minimal-effect levels in relation to natural occurrence and tolerated maximum concentrations. Natural occurrence of AFB1, DON and fumonisin vary with growing and storage conditions. Also, insect damage to kernels may increase toxin content. The annual quantity of contaminated material to be used in animal diets is quite variable. Therefore, knowledge on the variability and predictability (for example, see Hooker et al. 2002 for DON) of contamination levels is important. It should be noted, however, that many of the data on contamination levels are derived from non-random samples, usually biased upwards because monitoring programmes tend to focus on lots that are suspected to be contaminated.

The natural occurrence of AFB1 in the most important feed ingredients (maize, soyabeans, peanut meal and cottonseed meal) generally ranges between 0 and $1 \mathrm{mg} / \mathrm{kg}$, although higher contamination levels have been reported occasionally. Surveys of cottonseed and cottonseed meal showed an 8 and $19 \%$ incidence, respectively, with average AFB1 concentrations of 0.143 and $0.099 \mathrm{mg} / \mathrm{kg}$, respectively (Lillehoj, 1979). A survey of field maize showed that $32 \%$ of the samples contained more than $0.020 \mathrm{mg} \mathrm{AFB} 1 / \mathrm{kg}$. Regional variation between 0 and $0 \cdot 6$ mg AFB $1 / \mathrm{kg}$ was observed (Lillehoj, 1979). According to the World Health Organization (1998), $4 \%$ of the total maize in the USA contains more than $0.02 \mathrm{mg} \mathrm{AFB} 1 / \mathrm{kg}$. A recent survey of Brazilian maize showed AFB1 contamination in $54 \%$ of the samples, with concentrations varying between 0.006 to $1.6 \mathrm{mg} / \mathrm{kg}$, averaging $0.168 \mathrm{mg} / \mathrm{kg}$ (Machinski et al. 2001). In the Netherlands a maximum of $0.02 \mathrm{mg} \mathrm{AFB} 1 / \mathrm{kg}$ is tolerated in diets for pigs and poultry (Productschap voor Veevoeder, 2001). In Texas, USA (Latimer, 2002), a maximum of $0.2 \mathrm{mg} / \mathrm{kg}$ is tolerated in feedstuffs to be used in pig diets. For AFB1, the estimated 5 GRC $(0.3$ and $1 \mathrm{mg} / \mathrm{kg}$ for pigs and poultry, respectively) is well within the range of natural occurrence of AFB1 in feed ingredients. Aflatoxins may reduce pig performance even at concentrations below $0 \cdot 3 \mathrm{mg} / \mathrm{kg}$ to a significant extent. Unfortunately, the estimated 5GRC was outside the measured range in the experiments used for the regression analysis (Table 1), urging the need for more reliable data within this range. For broilers, contamination with AFB1 is probably not limiting growth performance.

For DON, natural occurrence generally ranges between 0 and $5 \mathrm{mg} / \mathrm{kg}$, although contamination levels above 40 $\mathrm{mg} / \mathrm{kg}$ have been reported (see Rotter et al. 1996a; Hooker et al.2002). In 1996, an epidemic year in the USA, ten out of fourteen investigated truckloads of wheat had concentrations above $1 \mathrm{mg} / \mathrm{kg}$, averaging $7.8 \mathrm{mg} / \mathrm{kg}$ (Hart \& Schabenberger, 1998). In 1996, analysis of maize samples, obtained over 750 maize fields in Nebraska, Illinois and Iowa, representing $50 \%$ of the US maize crop, revealed $6.8 \%$ of the samples contained concentrations above $1 \mathrm{mg} / \mathrm{kg}$ (United States Department of Agriculture, 1996). Hooker et al. (2002), monitoring DON concentrations in winter wheat on 399 farm fields in Ontario, Canada from 1996 to 2000, demonstrated average DON concentrations of $8 \cdot 0,0 \cdot 8,0 \cdot 3,0.9$ and $1.6 \mathrm{mg} / \mathrm{kg}$ from 1996 to 2000 , respectively. The percentage of fields with concentrations above $1 \mathrm{mg} / \mathrm{kg}$ was 94, 40,11, 24 and $55 \%$ from 1996 to 2000, respectively. In the USA, the Food and Drug Administration has issued advisory guidelines of maximum

Table 7. Summary of the effect of deoxynivalenol, fumonisin and aflatoxin on pigs and broilers*

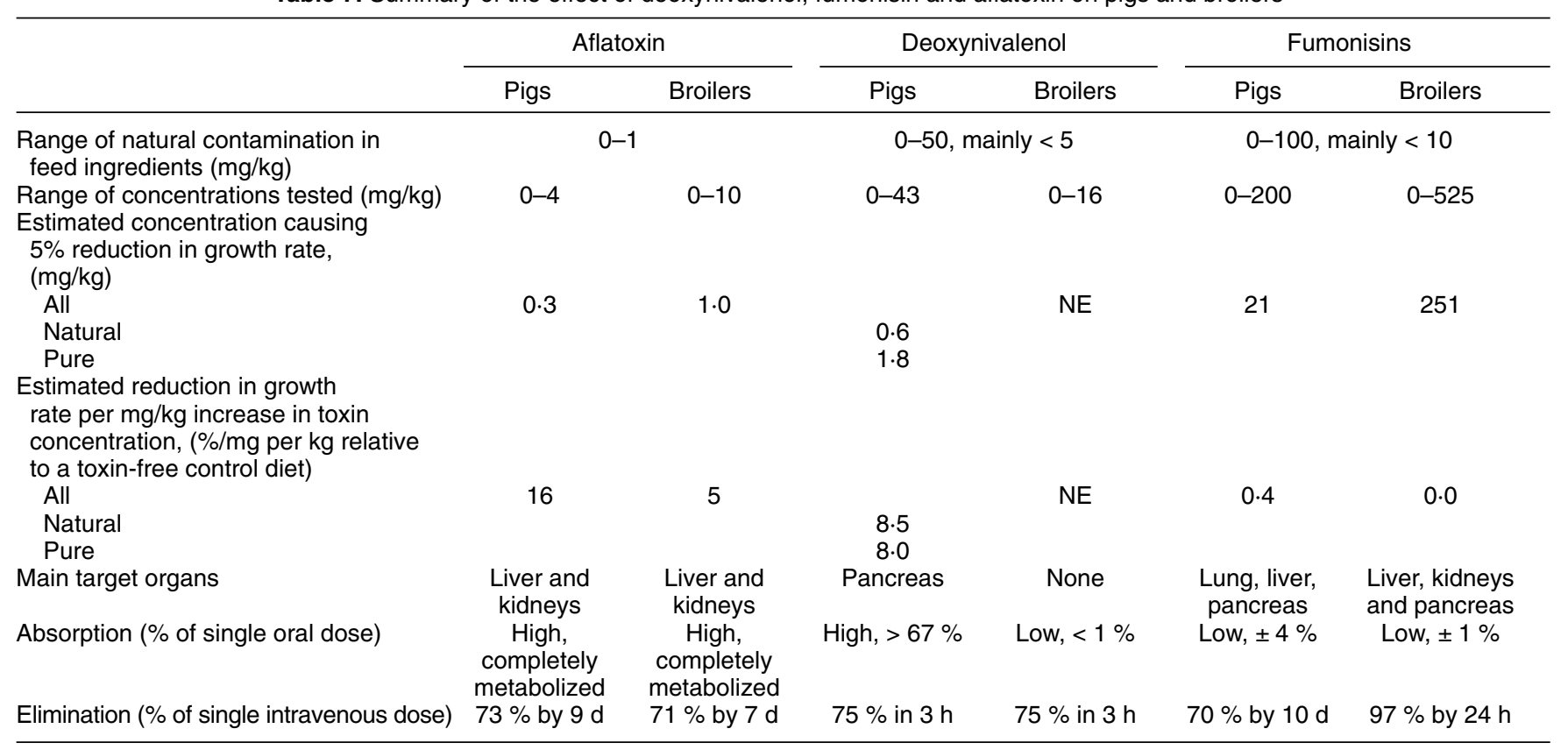

NE, not estimable.

* Data analysed as presented on p. 224. 
DON concentrations of 1 and $5 \mathrm{mg} / \mathrm{kg}$ for pig and poultry diets. In the Netherlands, a maximum of 1 and $3 \mathrm{mg}$ $\mathrm{DON} / \mathrm{kg}$ is tolerated in pig and poultry diets, respectively (Productschap voor Veevoeder, 2001). The estimated 5GRC for pigs $(0.6$ and $1.8 \mathrm{mg} / \mathrm{kg}$ for natural and pure contaminated diets), but not for poultry, are well within the range of natural occurrence of DON. Together with the large impact DON has on pig performance (MGR of $8 \% / \mathrm{mg}$ per $\mathrm{kg}$ ), this illustrates the importance of reliable data on the effects of DON concentrations below $3 \mathrm{mg} / \mathrm{kg}$.

Natural occurrence of FB1 usually ranges between 0 and $10 \mathrm{mg} / \mathrm{kg}$, but is highly variable between regions, and concentrations above $100 \mathrm{mg} / \mathrm{kg}$ have been observed occasionally (see Dutton, 1996). In the United States Department of Agriculture (1996) report, analysis of the maize samples referred to earlier, representing $50 \%$ of the US maize crop, revealed $3.9 \%$ of the samples contained concentrations above $5 \mathrm{mg} / \mathrm{kg}$. The overall average was around $1 \mathrm{mg} / \mathrm{kg}$ (United States Department of Agriculture, 1996). Diaz \& Boermans (1994) reviewed data of maize-based animal feeds from different countries and reported FB1 concentrations ranging from 0 to $5 \mathrm{mg} / \mathrm{kg}$. About one-third of the samples tested contained detectable FB1 concentrations. The Food and Drug Administration has recently recommended 10 and $50 \mathrm{mg} / \mathrm{kg}$ as the maximum levels for total fumonisins in diets for pigs and poultry, respectively. The naturally occurring concentrations of FB1 in feed ingredients are far below the estimated 5GRC for broilers (251 $\mathrm{mg} / \mathrm{kg})$. For pigs, the estimated 5GRC $(21 \mathrm{mg} / \mathrm{kg})$ is also below, but much closer to, the range of natural contamination. Based on this analysis, it may be concluded that FB1 contamination is probably not a problem for broiler production, but in some cases can be a problem for pig production. In addition, it should be noted that the available information for pigs at contamination levels below $50 \mathrm{mg} / \mathrm{kg}$ is not sufficient.

Comparative toxicity in relation to absorption and elimination kinetics. As described earlier, in both pigs and poultry, aflatoxins are rapidly absorbed and slowly excreted. Data of Lüthy et al. (1980) for pigs and Sawhney et al. (1973) for laying hens show quite comparable absorption and elimination kinetics of radioactivity for AFB1. It is uncertain whether the data from Sawhney et al. (1973) are representative for broilers. Nevertheless, it is improbable that the large difference in sensitivity between pigs and broilers (MGR of 16 and $5 \% / \mathrm{mg}$ per $\mathrm{kg}$, respectively) can be entirely attributed to differences in absorption and elimination kinetics.

Pigs appeared to be far more sensitive to DON exposure than poultry. This difference in sensitivity corresponds to a difference in absorption kinetics. As described earlier (see also Rotter et al. 1996a), systemic absorption of DON by poultry is probably close to $1 \%$ of the ingested dose, while in pigs, $68 \%$ of an intragastric dose was recovered in urine within $24 \mathrm{~h}$.

The low sensitivity of poultry to dietary FB1 exposure when compared with pigs corresponds to a difference in absorption and elimination kinetics. As described earlier, absorption is low in both pigs and layer hens; absorption accounted for 4 and $1 \%$ of the administered dose in pigs and layer hens, respectively (Prelusky et al. 1996b). This may, however, be slightly underestimated, because of a possible clearance at first-pass by the liver (Prelusky et al. 1996b). Elimination of a single iv dose of FB1, strongly depending on biliary secretion, takes more time for pigs compared with layer hens; $80 \%$ within $72 \mathrm{~h}$ and $99 \%$ within 24 h, respectively. In pigs, Prelusky et al. (1996a,b) also found accumulating tissue residues after prolonged exposure to a constant level of dietary FB1, and attributed this to enterohepatic circulation. It therefore seems that the low sensitivity of pigs and poultry to dietary FB1 in general is related to low systemic absorption $(<5 \%$ of oral supply). The higher sensitivity of pigs when compared with poultry is probably related to slower elimination kinetics in pigs.

Adaptive responses to prolonged intakes. When considering their growth performance, neither pigs nor broilers seem to adapt when exposed to prolonged intakes of a diet with a constant dietary concentration of AFB1. Harvey et al. (1989) and Armbrecht et al. (1971) reported a consistent depression in growth performance of pigs throughout 4 and 16 weeks exposure periods, respectively. Randall \& Bird (1979) as well as Mani \& Sundaresan (1998) showed a consistent effect on growth depression during AFB1 exposure in broilers. This lack of adaptation is probably related to the rate of absorption exceeding the rate of elimination from the body, as described previously. This implies that at prolonged exposure, AFB 1 and its metabolites accumulate in tissues. The animals will decrease their intake to minimize the toxic effects of AFB1.

Pigs do adapt to prolonged intakes of DON. The depression in feed intake and growth by DON is the most severe in the first week after exposure (Pollmann et al. 1985; Foster et al. 1986; Friend et al. 1986a). Rotter et al. (1994) observed that pigs fed DON in concentrations up to $3 \cdot 0$ $\mathrm{mg} / \mathrm{kg}$ diet had significantly decreased weight gain over the initial $7 \mathrm{~d}$ of exposure. However, pigs adapted to dietary DON and at the end of the 4-week experimental period, the rates of gain did not differ between toxin-free control and contaminated diets. Pollmann et al. (1985) observed that the decrease in gain compared with the toxin-free control treatment was 81,48 and $24 \%$ in week 1,2 and 3 respectively, for pigs receiving $2.8 \mathrm{mg} \mathrm{DON} / \mathrm{kg}$ diet, indicating a clear adaptation of pigs to DON. Pigs showed a similar adaptive response to pure DON as compared with naturally contaminated DON (Foster et al. 1986). Trenholm et al. (1994) reported that the severe growth depression of pigs fed pure DON diets occurred mainly during the first $3 \mathrm{~d}$. The rapid clearance of DON from the body, described previously, is probably a permissive factor for this adaptation process.

The data of Weibking et al. (1993) and Wu et al. (1995) suggest that the response in growth rate of broilers to prolonged intakes of FB1 does not decrease. Data on pig performance in response to prolonged intakes of FB1 are scarce. The work of Colvin et al. (1993), although based on only five pigs, suggests an increased reduction in growth rate with increasing exposure to a diet containing 
$200 \mathrm{mg}$ FB1 $/ \mathrm{kg}$. Also, the growth rates obtained by Rotter et al. (1996b), exposing male piglets for 8 weeks to FB1 concentrations varying from 0 to $10 \mathrm{mg} \mathrm{FB} 1 / \mathrm{kg}$, did not show any sign of adaptation to prolonged intakes. The lack of adaptation of growth rates to prolonged FB1 intakes corresponds with the observation of Prelusky et al. $(1996 a, b)$ that FB1 accumulates in tissues after prolonged exposure.

Effect of toxin intake on protein and energy metabolism. As shown throughout the present paper, the effects of the three toxins studied on feed efficiency are not always consistent. Diet composition is one of the variables between studies. As illustrated by Coffey et al. (1989), adverse effects of aflatoxin on live-weight gain could be compensated for by increased protein or lysine intakes. Bodyweight gain is the net result of protein, water and fat retention. The effects of some toxins such as DON (Rotter et al. 1996a) may specifically interfere with protein synthesis. Others may, by various mechanisms, alter the energy metabolism, or do both. Following the classical theory of protein- and energy-dependent phases in protein gain in pigs (for example, see Whittemore \& Fawcett, 1976; Bikker et al. 1994), energy intake may limit protein retention in some types of animals, while, in others, protein intake may be limiting. In a particular situation, effective nutritional strategies would include adaptation of the protein:energy in the diet. The hypothesis that toxins may suppress protein retention (probably by reducing protein synthesis) is strengthened by the observations that effects of toxin intake are generally larger in animals with a relatively high rate of protein retention. For example, effects are larger in: (1) males $v$. females (see Rotter et al. 1996b for FB1; Cote et al. 1985 and Friend et al. $1986 a$ for DON); (2) young animals $v$. older animals. Measurement of protein and energy metabolism in response to toxin intake will give valuable information on the mode of action and on the quantitative importance of the effects of toxins at low levels of intake, which are difficult to establish in conventional growth trials.

\section{Conclusions}

It was estimated that with each $\mathrm{mg} / \mathrm{kg}$ increase of AFB 1 in the diet the growth rate would be depressed by $16 \%$ for pigs and $5 \%$ for broilers. For DON, with each $\mathrm{mg} / \mathrm{kg}$ increase in the diet, the growth depression (MGR) was estimated at about $8 \%$ for pigs, while broilers showed no response to DON concentrations below $16 \mathrm{mg} / \mathrm{kg}$. FB1 showed the lowest impact on growth performance; with each $\mathrm{mg} / \mathrm{kg}$ increase, the depression in growth rate was estimated at 0.4 and $0.0 \% / \mathrm{mg}$ per $\mathrm{kg}$ for pigs and broilers, respectively. Dietary concentrations that cause a $5 \%$ reduction in growth rate were estimated at: 0.3 and $1.0 \mathrm{mg} / \mathrm{kg}$ for AFB1 for pigs and broilers, respectively; 1.8 and $0.6 \mathrm{mg} / \mathrm{kg}$ for pure and naturally contaminated DON for pigs, respectively; 21 and $251 \mathrm{mg} / \mathrm{kg}$ for FB1 for pigs and broilers, respectively. Pigs clearly adapt to prolonged exposure to DON. Existing data suggest no adaptive responses of pigs or broilers to prolonged intake of FB1 or AFB1.
The magnitude of the adverse effects decreases in the order AFB1, DON, FB1. Differences in the MGR, however, are only partly related due to differences in absorption and elimination kinetics. Most importantly, they depend on the toxicity of the toxin molecule post-absorption. Natural toxin occurrence varies with growing and storage conditions. Generally, this varies between 0 and $1 \mathrm{mg} / \mathrm{kg}$ for AFB 1 and between 0 and $10 \mathrm{mg} / \mathrm{kg}$ for DON and FB1. Considering the natural occurrence of the toxins, effects on broiler performance are relatively unimportant when compared with pigs. More knowledge on the effects of AFB1 concentrations below $0.3 \mathrm{mg} / \mathrm{kg}$ and of DON concentrations below $3 \mathrm{mg} / \mathrm{kg}$ on pig performance is important. For FB1, more information on concentrations between 10 and $50 \mathrm{mg} / \mathrm{kg}$ could greatly improve the accuracy of estimations of MGR and 5GRC. Furthermore, effects of toxin intake on immune parameters, reported in the literature, necessitates research on toxin-environment interactions.

\section{Acknowledgement}

The financial support of RENESSEN LLC for conducting this study is gratefully acknowledged.

\section{References}

Armbrecht BH, Wiseman HG, Shalkop WT \& Geleta JN (1971) Swine aflatoxicosis. 1. An assessment of growth efficiency and other responses in growing pigs fed aflatoxin. Environmental Physiology 1, 198-208.

Bergsjø B \& Kaldhusdal M (1994) No association found between the ascites syndrome in broilers and feeding of oats contaminated with deoxynivalenol up to thirty-five days of age. Poultry Science 73, 1758-1762.

Bikker P, Verstegen MWA, Campbell RG \& Kemp B (1994) Digestible lysine requirement of gilts with high genetic potential for lean gain, in relation to the level of energy intake. Journal of Animal Science 72, 1744-1753.

Brown TP, Rottinghaus GE \& Williams ME (1992) Fumonisin mycotoxicosis in broilers: performance and pathology. Avian Diseases 36, 450-454.

Carlson RL, Fritschen RD, Peo ER Jr, Lewis AJ \& Crenshaw JD (1983) Effect of vomitoxin contaminated wheat and copper addition in weanling pig diets. Journal of Animal Science 57, Suppl. 1, 239.

Clarkson JR (1979) Aflatoxicosis in swine: a review. Forum Newsletter 12, no. 4, November 1979.

Coffey MT, Hagler WM Jr \& Cullen JM (1989) Influence of dietary protein, fat or amino acids on the response of weaning swine to aflatoxin B1. Journal of Animal Science 67, 465-472.

Colvin BM, Cooley AJ \& Beaver RW (1993) Fumonisin toxicosis in swine: Clinical and pathologic findings. Journal of Veterinary Diagnostic Investigation 5, 232-241.

Colvin BM \& Harrison LN (1992) Fumonisin-induced pulmonary edema and hydrothorax in swine. Mycophathologia 117, 79-82.

Cote LM, Beasley VR, Bratich PM, Swanson SP, Shivaprasad HL \& Buck WB (1985) Sex-related reduced weight gains in growing swine fed diets containing deoxynivalenol. Journal of Animal Science 61, 942-950.

Diaz GJ \& Boermans HJ (1994) Fumonisin toxicosis in domestic animals: a Review. Veterinary Human Toxicology 36, 548-555.

Doerr A, Huff WE, Wabeck CJ, Chaloupka GW, May JD \& Merkley JW (1983) Effects of low level chronic aflatoxicosis in broiler chickens. Poultry Science 62, 1971-1977. 
Dutton MF (1996) Fumonisins, mycotoxins of increasing importance: their nature and their effects. Pharmacology and Therapeutics 70, 137-161.

Eaton DL, Ramsdell HS \& Neal GE (1994) Biotransformation of aflatoxins. In The Toxicology of Aflatoxins. Human Health, Veterinary and Agricultural Significance, pp. 45-71 [DL Eaton and JD Groopman, editors]. San Diego, CA: Academic Press.

Espada Y, Ruiz de Gopegui R, Cuadradas C \& Cabañes FJ (1994) Fumonisin mycotoxicosis in broilers. Weights and serum chemistry modifications. Avian Diseases 38, 454-460.

Forsyth DM, Yoshizawa T, Morooka N \& Tuite J (1977) Emetic and refusal activity of deoxynivalenol in swine. Applied Environmental Microbiology 34, 547-552.

Foster BC, Trenholm HL, Friend DW, Thompson BK \& Hartin KE (1986) Evaluation of different sources of deoxynivalenol (vomitoxin) fed to swine. Canadian Journal of Animal Science 66, 1149-1154.

Friend DW, Trenholm HL, Elliot JI, Thompson BK \& Hartin KE (1982) Effect of feeding vomitoxin-contaminated wheat to pigs. Canadian Journal of Animal Science 62, 1211-1222.

Friend DW, Trenholm HL, Thompson BK, Fiser PS \& Hartin KE (1986a) Effect of feeding diets containing deoxynivalenol (vomitoxin)-contaminated wheat or corn on the feed consumption, weight gain, organ weight and sexual development of male and female pigs. Canadian Journal of Animal Science 66, 765-775.

Friend DW, Trenholm HL, Thompson BK, Prelusky DB \& Hartin KE (1986b) Effect of deoxynivalenol (DON)-contaminated diet fed to growing-finishing pigs on their performance at market weight, nitrogen retention and DON excretion. Canadian Journal of Animal Science 66, 1075-1085.

Giambrone JJ, Diener UL, Davis ND, Panangala VS \& Hoerr FJ (1985) Effects of aflatoxin on young turkeys and broiler chickens. Poultry Science 64, 1678-1684.

Guzman RE, Casteel SW, Rottinghaus GE \& Turk JR (1997) Chronic consumption of fumonisins derived from Fusarium moniliforme culture material: Clinical and pathologic effects in swine. Journal of Veterinary Diagnostic Investigation 9, 216-218.

Harrison LR, Colvin BM, Greene JT, Newman LE \& Cole JR (1990) Pulmonary edema and hydrothorax in swine produced by fumonisin B1, a toxic metabolite of Fusarium moniliforme. Journal of Veterinary Diagnostic Investigation 2, 217-221.

Hart LP \& Schabenberger O (1998) Variability of vomitoxin truckloads of wheat in a wheat scab epidemic year. Plant Disease 82, 625-630.

Harvey RB, Edrington TS, Kubena LF, Elissalde MH \& Rottinghaus GE (1995a) Influence of aflatoxin and fuminisin B1-containing culture material on growing barrows. American Journal of Veterinary Research 56, 1668-1672.

Harvey RB, Huff WE, Kubena LF \& Phillips TD (1989) Evaluation of diets cocontaminated with aflatoxin and ochratoxin fed to growing pigs. American Journal of Veterinary Research 50, 1400-1405.

Harvey RB, Kubena LF \& Elissalde MH (1995b) Effects of aflatoxin on tocopherol and retinol concentrations in growing barrows. Agri-Practice 16, 12-14.

He P, Young LG \& Forsberg C (1993) Microbially detoxified vomitoxin-contaminated corn for young pigs. Journal of Animal Science 71, 963-967.

Hooker DC, Schaafsma AW \& Tamburic-Illincic L (2002) Using weather variables pre- and post-heading to predict deoxynivalenol in winter wheat. Plant Disease 86, 611-619.

Hsieh DPH (1979) Basic metabolic effects of mycotoxins. In Interactions of Mycotoxins in Animal Production. Proceedings of a Symposium, July 13, 1978, Michigan State University, 1979, pp. 43-55. Washington, DC: National Academy of Sciences.

Hsieh DPH \& Wong JJ (1994) Pharmacokinetics and excretion of aflatoxins. In The Toxicology of Aflatoxins. Human Health, Veterinary, and Agricultural Significance, pp.73-88 [DL Eaton and JD Groopman, editors]. San Diego, CA: Academic Press.

Huff WE (1980) Evaluation of tibial dyschondroplasia during aflatoxicosis and feed restriction in young broiler chickens. Poultry Science 59, 991-995.

Huff WE, Kubena LF, Harvey RB, Hagler WM Jr, Swanson SP, Phillips TD \& Creger CR (1986) Individual and combined effects of aflatoxin and deoxynivalenol (DON, vomitoxin) in broiler chickens. Poultry Science 65, 1291-1298.

Hulan HW \& Proudfoot FG (1982) Effects of feeding vomitoxin contaminated wheat on the performance of broiler chickens. Poultry Science 61, 1653-1659.

Kubena LF, Edrington TS, Harvey RB, Buckley SA, Phillips TD, Rottinghaus GE \& Casper HH (1997) Individual and combined effects of fumonisin B1 present in Fusarium moniliforme culture material and T-2 toxin or deoxynivalenol in broiler chicks. Poultry Science 76, 1239-1247.

Kubena LF, Huff WE, Harvey RB, Corrier DE, Phillips TD \& Creger CR (1988) Influence of ochratoxin A and deoxynivalenol on growing broiler chicks. Poultry Science 67, 253-260.

Kubena LF, Huff WE, Harvey RB, Phillips TD \& Rottinghaus GE (1989) Individual and combined toxicity of deoxynivalenol and T-2 toxin in broiler chicks. Poultry Science 68, 622-626.

Latimer GW (2002) Distribution of aflatoxin-containing whole grain and whole seed in commercial channels and their use in mixed feeds. Feed Industry Memorandum no. 5-12. College Station, TX: Texas A\&M University.

Li YC, Ledoux DR, Bermudez AJ, Fritsche KL \& Rottinghaus GE (1999) Effects of fumonisin B1 on selected immune responses in broiler chicks. Poultry Science 78, 1275-1282.

Lillehoj EB (1979) Natural occurrence of mycotoxins in feeds: pitfalls in determination. In Interactions of Mycotoxins in Animal Production. Proceedings of a Symposium, July 13, 1978, Michigan State University, 1979, pp.139-153. Washington, DC: National Academy of Sciences.

Lindemann MD, Blodgett DJ, Kornegay ET \& Schurig GG (1993) Potential ameliorators of aflatoxicosis in weanling/growing swine. Journal of Animal Science 71, 171-178.

Lun AK, Young LG \& Lumsden JH (1985) The effects of vomitoxin and feed intake on the performance and blood characteristics of young pigs. Journal of Animal Science 61, 1178-1185.

Lüthy J, Zweifel U \& Schlatter CH (1980) Metabolism and tissue distribution of $\left[{ }^{14} \mathrm{C}\right]$ aflatoxin $\mathrm{B} 1$ in pigs. Food and Chemical Toxicology 18, 253-256.

Mabee MS \& Chipley JR (1973) Tissue distribution and metabolism of aflatoxin B1 $-{ }^{14} \mathrm{C}$ in layer chicks. Journal of Food Science 38, 566-570.

Machinski M Jr, Valente Soares LM, Sawazaki E, Bolonhezi D, Castro JL \& Bortolleto N (2001) Aflatoxins, ochratoxin A and zearalenone in Brazilian corn cultvars. Journal of the Science of Food and Agriculture 81, 1001-1007.

Mani K \& Sundaresan K (1998) Combined effects of aflatoxin B1 and spontaneous IBD exposure of commercial broilers. Cheiron 27, 59-62.

Motelin GK, Haschek WM, Ness DK, Hall WF, Harlin KS, Schaeffer DJ \& Beasley VR (1994) Temporal and doseresponse features in swine fed corn screenings contaminated with fumonisin mycotoxins. Mycopathologia 126, 27-40.

Øvernes G, Matre T, Sivertsen T, Larsen HJS, Langseth W, Reitan LJ \& Jansen JH (1997) Effects of diets with graded levels of 
naturally deoxynivalenol contaminated oats on immune response in growing pigs. Journal of Veterinary Medicine 44A, 539-550.

Panangala VS, Giambrone JJ, Diener UL, Davis ND, Hoerr FJ, Mitra A, Schultz RD \& Wilt GR (1986) Effect of aflatoxin on the growth performance and immune responses of weanling swine. American Journal of Veterinary Research 47, 2062-2067.

Pollmann DS, Koch BA, Seitz LM, Mohr HE \& Kennedy GA (1985) Deoxynivalenol-contaminated wheat in swine diets. Journal of Animal Science 60, 239-247.

Prabaharan S, Titus George V \& Balasubramaniam GA (1999) Influence of dietary aflatoxin and coccidiosis on growth rate in broiler chicken. Indian Veterinary Journal 76, 827-828.

Prelusky DB, Hamilton RMG, Trenholm HL \& Miller JD (1986) Tissue distribution and excretion of radioactivity following administration of ${ }^{14} \mathrm{C}$-labelled deoxynivalenol to white leghorn hens. Fundamental and Applied Toxicology 7, 635-645.

Prelusky DB, Hartin KE, Trenholm HL \& Miller JD (1988) Pharmacokinetic fate of ${ }^{14} \mathrm{C}$-labeled deoxynivalenol in swine. Fundamental and Applied Toxicology 10, 276-286.

Prelusky DB, Miller JD \& Trenholm HL (1996a) Disposition of ${ }^{14} \mathrm{C}$-derived residues in tissues of pigs fed radiolabelled fumonisin B1. Food Additives and Contaminants 13, 155-162.

Prelusky DB \& Trenholm HL (1992) Nonaccumulation of residues in swine tissues following extended consumption of deoxynivalenol-contaminated diets. Journal of Food Science 57, 801-802.

Prelusky DB, Trenholm HL, Rotter BA, Miller JD, Savard ME, Yeung JM \& Scott PM (1996b) Biological fate of fumonisin B1 in food-producing animals. Advances in Experimental Medicine and Biology 392, 265-278.

Productschap voor Veevoeder (2001) Diervoederwetgeving in Nederland. Den Haag, The Netherlands: Productschap voor Veevoeder.

Ram KV, Rao DG \& Rao PR (1988) Effect of aflatoxin feeding and its withdrawal effect on the growth rate of broilers and layers under long term feeding trials. Indian Veterinary Journal 65, 113-116.

Randall GM \& Bird FH (1979) The effect of exercise on the toxicity of aflatoxin B1 in chickens. Poultry Science 58, 1284-1288.

Reddy AR, Reddy VR, Rao PV \& Yadagiri B (1982) Effect of experimentally induced aflatoxicosis on the performance of commercial broiler chicks. Indian Journal of Animal Science 52, 405-410.

Rotter BA, Prelusky DB, Fortin A, Miller JD \& Savard ME (1997) Impact of pure fumonisin B1 on various metabolic parameters and carcass quality of growing-finishing swine - preliminary findings. Canadian Journal of Animal Science 77, 465-470.

Rotter BA, Prelusky DB \& Pestka JJ (1996a) Toxicology of deoxynivalenol (vomitoxin). Journal of Toxicology and Environmental Health 48, 1-34.

Rotter BA, Thompson BK, Lessard M, Trenholm HL \& Tryphonas H (1994) Influence of low-level exposure to Fusarium mycotoxins on selected immunological and hematological parameters in young swine. Fundamental and Applied Toxicology 23, 117-124.
Rotter BA, Thompson BK, Prelusky DB, Trenholm HL, Stewart B, Miller JD \& Savard ME (1996b) Response of growing swine to dietary exposure to pure fumonisin B1 during an eight-week period: Growth and clinical parameters. Natural Toxins 4, $42-50$.

Sawhney DS, Vadehra DV \& Baker RC (1973) The metabolism of ${ }^{14} \mathrm{C}$ aflatoxins in laying hens. Poultry Science 52, 1302-1309.

Scott PM (1991) Possibility of reduction or elimination of mycotoxins present in cereal grains. In Cereal Grain Mycotoxin, Fungi and Quality in Drying and Storage, pp. 529-572 [J Chelkowski, editor]. Amsterdam, The Netherlands: Elsevier.

Shukla SK \& Pachauri SP (1985) Effect of aflatoxicosis on growth and development in cockerels. Indian Veterinary Journal 62, 341-342.

Sodhi S, Brar APS \& Grewal GS (1996) Biochemical studies on combined immunomodulatory effects of aflatoxin and malathion in broiler chicks. Indian Journal of Poultry Science 31, 88-91.

Southern LL \& Clawson AJ (1979) Effects of aflatoxins on finishing swine. Journal of Animal Science 49, 1006-1011.

Trenholm HL, Foster BC, Charmley LL, Thompson BK, Hartin KE, Coppock RW \& Albassam MA (1994) Effects of feeding diets containing Fusarium (naturally) contaminated wheat or pure deoxynivalenol (DON) in growing pigs. Canadian Journal of Animal Science 74, 361-369.

United States Department of Agriculture (1996) Mycotoxin levels in the 1996 midwest preharvest corn crop. U.S. Department of Agriculture, Animal and Plant Health Inspection Service, Veterinary Services Information Sheet no. N222.1296, December 1996.

Vudathala DK, Prelusky DB, Ayroud M, Trenholm HL \& Miller JD (1994) Pharmacokinetic fate and pathological effects of ${ }^{14} \mathrm{C}$ fumonisin B1 in laying hens. Natural Toxins 2, 81-88.

Weibking TS, Ledoux DR, Bermudez AJ, Turk JR \& Rottinghaus GE (1993) Effects of feeding Fusarium moniliforme culture material, containing known levels of fumonisin B1, on the young broiler chick. Poultry Science 72, 456-466.

Whittemore CT \& Fawcett RH (1976) Theoretical aspects of a flexible model to simulate protein and lipid growth in pigs. Animal Production 22, 87-96.

World Health Organization (1998) Safety evaluation of certain food additives and contaminants. Aflatoxins. WHO Food Additives Series PG, pp. 361-468. Geneva, Switzerland: WHO.

Wu W, Li G \& Liu T (1995) The effect of fumonisin B1 on isolated chondrocytes and on bone formation. Poultry Science 74, 1431-1436.

Young LG, McGirr L, Valli VE, Lumsden JH \& Lun A (1983) Vomitoxin in corn fed to young pigs. Journal of Animal Science 57, 655-664.

Zomborszkyne-Kovacs M, Vetesi F, Kovacs F, Bata A, Repa I \& Horn P (2000) A fusarium moniliforme fumonizin-B1 toxinjanak toleralhato hatarertekere es perinatalis toxikozist eloidezo hatasara vonatkozo vizsgalatok sertesben (Investigations on the tolerable limit values and the perinatal toxic effect of mycotoxins produced by fusarium moniliforme). Mayar-AllatorvosokLapja 122, 168-175. 
https://doi.org/10.1079/NRR200368 Published online by Cambridge University Press 